\title{
RELAÇÃO PROCESSADOR LINGÜÍSTICO-GRAMÁTICA EM PERSPECTIVA: PROBLEMAS DE UNIFICAÇÃO EM CONTEXTO MINIMALISTA*
}

\author{
(Processor-grammar relationship in perspective: \\ unification problems in minimalist context)
}

\author{
Letícia Maria Sicuro CORRÊA \\ (PUC-Rio/LAPAL)
}

\begin{abstract}
RESUMO: A possibilidade de uma derivação minimalista representar a computação sintática implementada em tempo real é considerada. Parte-se de um histórico da relação entre Lingüística Gerativista e Psicolingüística, ressaltando-se o que há de convergente entre esses campos a partir do Minimalismo. Duas dificuldades para a unificação processador-gramática em um único algoritmo são identificadas: a direcionalidade (ascendente) da derivação ante a incrementalidade do processamento lingüístico; a necessidade de se prever movimento sintático com e sem custo. Propõe-se um modelo misto (descentelascendente) no qual a direcionalidade da computação on-line é função do modo como elementos de categorias funcionais e lexicais se relacionam com o sistema conceitual/intencional na língua em uso. Apenas movimento sintático que responde a demandas discursivas é implementado em tempo real.

PaLAVRAS-CHAVE: Unificaşão; minimalismo; incrementalidade; movimento sintático.
\end{abstract}

ABSTRACT: The possibility of a minimalist derivation to represent on-line computation is considered. The relationship between Generative Linguistics and Psycholinguistics is put in perspective in order to bighlight convergent developments. Two difficulties are identified in the unification grammar-language processor in a single algorithm: The

* Este artigo é uma versão ampliada do trabalho apresentado na sessão coordenada Processamento lingüístico e derivação minimalista: compatibilidade ou identidade? do IX Congresso Internacional da ABRALIN, Brasília, 17-19/02/2005 (Corrêa, 2005a). Foi realizado como parte das atividades vinculadas ao projeto CNPq 308713/2005-2, no âmbito do Grupo de Pesquisa Processamento e Aquisição da Linguagem (www.dgp.cnpq.br), do LAPAL/PUC-Rio (Laboratório de Psicolingüística e Aquisição da Linguagem). Agradeço aos participantes do GPPAL pela discussão das idéias aqui veiculadas e particularmente a Marina Augusto, com quem estas vêm sendo sistematicamente exploradas, e a Mercedes Marcilese, pela leitura e revisão do texto e ajuda na bibliografia. Possíveis inadequações são, não obstante, de minha exclusiva responsabilidade. 
directionality of the derivation (bottom-up), vis-à-vis incremental processing; predicting costly and uncostly syntactic movement. A top-down/bottom-up model is proposed in which the directionality of the computation is a function of the relationship between elements of functional and lexical categories with the conceptual/intentional system, is actual language use. Syntactic movement that stems from discourse demands is the sole movement operation implemented on-line.

KEY-WORDS: Unification problem; minimalism; incrementality; syntatic movement.

\section{Introdução}

Uma questão fundamental, no estudo da língua como fenômeno cognitivo, diz respeito ao modo como conhecimento lingüístico é posto em uso na fala, ou seja, à relação entre processador lingüístico e gramática. Uma gramática gerativa apresenta uma teoria da computação lingüística, representando a língua (interna) em estado virtual. Processador lingüístico é o aparato cognitivo responsável pela condução da computação lingüística em tempo real (on-line), como na produção e na compreensão de enunciados verbais. Seu modo de operação pode ser caracterizado funcionalmente, como em modelos psicolingüísticos, ou de modo mais próximo à implementação física, em modelos neurocognitivos, do cérebro em atividade. Ainda que se espere que modelos da língua em estado virtual e em uso sejam compatíveis, a compatibilização entre estes não é de fácil efetivação (cf. Fodor, Bever \& Garrett, 1974; Bresnan, 1978; Phillips, 1996).

Neste artigo, discute-se em que medida uma derivação minimalista pode ser incorporada em modelos de processamento lingüístico, de forma a caracterizar, funcionalmente, o modo de implementação da computação sintática efetivamente conduzida na formulação (ou codificação gramatical) e na análise sintática (parsing) de enunciados lingüísticos. Diferentemente de outras abordagens para este problema, que vêm sendo conduzidas de um ponto de vista estritamente formal (Phillips, 1996; 2003a; Chesi, 2004; Fong, 2005), parte-se da perspectiva do processamento lingüístico, conduzido a partir de uma intenção de fala, por parte do falante, a qual é pressuposta pelo ouvinte. ${ }^{1}$

1. Falante e ouvinte são termos usados de forma genérica independentemente de modalidade lingüística (oral/escrita), do meio físico em que a língua se realiza (sons vocais, sinais gestuais/ faciais) e do modo como o estímulo lingüístico é percebido (auditiva ou visualmente). 
A relação processador lingüístico-gramática apresenta-se como um aspecto do chamado problema de unificação. Este é inerente ao desenvolvimento das ciências naturais, que transcorre em termos de diferenciação e integração, no que concerne ao tratamento de um fenômeno comum (Polikarov, 1995). ${ }^{2}$ Trazido para o âmbito da ciência cognitiva, o problema da unificação remete, por um lado, à questão, de ordem filosófica, concernente à relação mente-corpo $($ Lycan, 2003) 3 e, por outro, põe em discussão, a possibilidade de integração entre os diferentes níveis com que tradicionalmente é concebido o tratamento de sistemas de processamento de informação (cf. Marr, 1982; Pylyshyn, 1984) ${ }^{4}$. No que concerne especificamente à língua, não só a possibilidade de integração de diferentes níveis de abordagem é considerada (do mais abstrato, no qual as propriedades de operações computacionais são definidas, ao mais físico ou cerebral), como, mais fundamentalmente, discute-se a possibilidade de se integrar o estudo da língua - conhecimento, aquisição, uso, evolução -, nas ciências naturais (Jenkins, 2000; Chomsky, 2000a). ${ }^{5}$

2. Os termos integração e unificação admitem uso indiferenciado, quando remetendo à dinâmica da ciência (cf. Polikarov, 1995). No contexto específico da ciência da computação, unificaçãa diz respeito à possibilidade de substituição das variáveis de uma fórmula, de modo a torná-la idêntica a uma outra (Knight, 1989). O problema da unificação no contexto da ciência cognitiva pode ser entendido em termos de integração entre modelos, admitindo-se a possibilidade de se considerar uma descrição - como, por exemplo, a de computação virtual - como equivalente a outra - no caso, a de computação em tempo real.

3. Há diferentes posturas quanto a essa questão, no contexto da Filosofia da Mente (cf. Lycan, 1993 e referências ali contidas). A visão de que a atividade mental é implementada no cérebro é, não obstante, consensual e pressuposta nas ciências cognitivas em geral, embora isso não signifique necessariamente assumir a chamada Teoria da Identidade (Place, 1960; Smart, 1981). Assim sendo, quando se considera aqui uma possível identificação entre derivação e computação on-line, o termo identificaşão deve ser entendido no sentido de equivalência entre modelos, como na nota 2.

4. Marr (1982) distingue os níveis de descrição de sistemas de processamento de informação como computacional, representacionallalgorítmico e implementacional (tendo como objeto o sistema da visão). O primeiro diz respeito, basicamente, às operações computacionais por meio das quais uma tarefa é conduzida. O segundo explicita o algoritmo por meio do qual a tarefa é desempenhada e as representações sobre as quais este opera. O nível mais baixo diz respeito ao modo de operação do aparato físico no qual a tarefa é implementada (o cérebro humano, um computador, etc). Pylyshym (1984) nomeia de semântico, simbólico ou sintático e biológico, os níveis que correspondem, grosso modo, aos definidos por Marr. Modelos conexionistas visam a aproximar os níveis funcional e implementacional (cf. Bogdan, 1993).

5. Nesse sentido, Chomsky chama atenção para o fato de a Química e a Física mostrarem-se irreconciliáveis, no século XIX, requerendo a constituição de novo campo para serem integradas, o que pode também ser requerido quando se considera a inserção da língua nesse contexto (Jenkins, 2000; Chomsky, 2004). 
Observa-se, de fato, grande convergência entre a concepção de derivação lingüística apresentada no contexto do PM e modelos de processamento, desenvolvidos de forma consideravelmente independente no contexto da Psicolingüística (particularmente, no que diz respeito a modelos simbólicos, com componentes modulares). Explorar essa convergência tem como vantagem a possibilidade de se tornar mais explícito, em modelos de processamento lingüístico, o modo como as ações de um formulador sintático (aparato responsável pela estruturação sintática de enunciados lingüísticos a partir de elementos recuperados do léxico na produção de enunciados) e de um parser (aparato responsável pela construção de estruturas sintáticas a partir do reconhecimento de uma seqüência de elementos do léxico, na compreensão) seriam informadas pela gramática virtual (a língua interna) - questão mal resolvida até então. Outra vantagem estaria na possibilidade de se fazerem previsões acerca do processamento lingüístico à luz de uma teoria lingüística, a serem verificadas em dados comportamentais ou neurocientíficos, que realimentariam aquela, descontando-se os fatores pertinentes às condição de processamento. Esse tipo de vantagem mostrase particularmente relevante para o estudo das afasias adquiridas e para o chamado déficit específico da linguagem (DEL) (Phillips, 1993a; Augusto, 2005; Corrêa, 2005b). Existem, no entanto, dificuldades para incorporação de uma derivação minimalista em modelos de processamento lingüístico, de forma a caracterizar um algoritmo de computação on-line.

Em primeiro lugar, os critérios de validação empírica que se impõem a modelos lingüísticos e psicolingüísticos são distintos. Modelos psicolingüísticos devem satisfazer aos critérios usualmente assumidos nas ciências naturais, quais sejam, gerar previsões a serem verificadas mediante os resultados de um teste de hipóteses, no qual um ou mais fatores passíveis de afetar o processamento lingüístico são tomados como variáveis independentes e o efeito dos mesmos e de uma possível interação entre estes é aferido com base em medidas comportamentais tomadas como variáveis dependentes - número de respostas de determinado tipo, tempo de reação a um dado evento, tempo de execução de uma tarefa ${ }^{6}$. Já para um modelo formal de língua, os critérios de validação empírica lhe são peculiares. Por um lado, equivalem àqueles que se aplicam a gramáticas formais (de lín-

6. Medidas comportamentais podem vir a ser complementadas com medidas da atividade neurofisiológica do cérebro, já no contexto da Neurociência Cognitiva. 
guas naturais e artificiais) - o modelo deve ser capaz de gerar todas as sentenças bem-formadas da língua e somente elas. Por outro, o modelo deve atender a critérios de adequação explanatória - apresentar conhecimento passível de ser adquirido naturalmente, tal como ocorre na aquisição de línguas maternas, em função das propriedades atribuídas ao estado inicial desse processo (GU - Gramática Universal). Mais recentemente, contudo, no contexto do Programa Minimalista (PM) (Chomsky, 1995a; 2007), os requisitos de validação empírica da teoria de língua apresentada passaram a ir "além da adequação explanatória”. A busca por explicações fundamentadas (principled explanations) para a constituição e modo de operação do sistema da língua, i.e, explicações que possam ser justificadas nos termos dos sistemas biológicos nos quais este se inclui, passou a fazer parte da agenda da teoria lingüística (Chomsky, 2005). Nessa direção, tem-se, a caracterização de uma faculdade de linguagem como produto de uma conjuntura de fatores decorrentes da evolução da espécie ${ }^{7}$, o que possibilita a existência de um sistema computacional de natureza, em princípio, específica (faculdade de linguagem em sentido restrito), que opera sobre elementos de um léxico — unidades de ordem representacional que pressupõem interação com outros domínios da cognição (unidades de um léxico), de forma tal que as expressões geradas necessariamente constituam interfaces entre a língua e os sistemas sensório-motor e conceitual-intencional que viabilizam a fala. Tem-se assim, portanto, a idéia de que a forma das línguas humanas é restringida pelas propriedades do aparato que viabiliza o processamento lingüístico. Diante disso, tomar uma derivação minimalista como representação da computação conduzia efetivamente por este aparato apresenta-se como uma possibilidade.

Dois problemas são aqui apontados que inviabilizam uma completa identificação entre uma derivação minimalista e uma caracterização funcional da computação on-line, quais sejam, (i) a direcionalidade da derivação ante o caráter incremental do processamento lingüístico, conduzido da esquerda para direita ao longo do tempo; (ii) o custo computacional diferenciado associado a diferentes tipos de operação de movimento caracterizadas na teoria lingüística.

7. Chomsky (2005) utiliza-se do conceito de exaptação, introduzido por Gould (1991) - processo evolutivo pelo qual mudanças decorrentes de adaptação seletiva criam condições favoráveis para o surgimento de relações ou processos de natureza distinta daqueles que passaram pelas mudanças , de modo a explicar a existência de condições favoráveis à existência de línguas na espécie humana. 
Com vistas a explorar a convergência constatada entre a proposta minimalista e modelos psicolingüísticos, ao mesmo tempo em que levando em conta os problemas apontados, soluções para os mesmos são encaminhadas, no contexto do que aqui denominamos tentativamente de uma teoria integrada da competência lingüística, ou seja, uma teoria que visa a caracterizar o modo como o conhecimento lingüístico representado em estado virtual em um modelo formal de língua é posto em uso na produção e na compreensão da linguagem. Nesse contexto, torna-se relevante considerar a relação que se estabelece entre os elementos do léxico que tomam parte na computação lingüística e os sistemas cognitivos que necessariamente interagem com a língua para que o desempenho lingüístico se realize, quando da produção/ compreensão de enunciados; e a possibilidade de operações que descrevem posicionamento de constituintes em sua posição canônica não serem implementadas, uma vez que parâmetros de ordem se encontrem fixados.

O presente artigo se insere em um campo interdisciplinar. Dois tipos de leitor são tomados como referência: aquele que se vê inserido no campo da Psicolingüística, com interesse na construção de modelos de processamento, conhecimento básico de lingüística gerativista, mas não necessariamente do PM; e aquele que se insere na teoria lingüística gerativista, empenhado no desenvolvimento de um modelo da língua interna, e com pouco contato ou familiaridade com a trajetória da Psicolingüística. Assim sendo, o texto deverá suprir algum conhecimento básico para cada um desses leitores, de modo a possibilitar a apreciação da convergência entre os dois campos teóricos aqui considerados.

Os objetivos deste artigo são: (i) trazer um breve histórico da relação entre Lingüística e Psicolingüística, apontando para a convergência que se estabelece entre a concepção minimalista de derivação lingüística e modelos processamento lingüístico; (ii) discutir em que medida uma derivação minimalista pode ser tomada como representação dos processos efetivamente implementados quando da formulação (ou codificação gramatical) e análise (parsing) de enunciados lingüísticos na produção e na compreensão da linguagem, respectivamente; (iii) apresentar direcionamentos para a solução dos problemas encontrados na identificação processador lingüístico/gramática, no contexto do que chamados de uma teoria integrada da competência lingüística. 
Este artigo se organiza da seguinte forma. A seção 1 traz um breve histórico da relação entre Lingüística e Psicolingüística, recapitulando a proposta da Teoria da Complexidade Derivacional dos anos 60, e enfatiza a convergência que se pode observar no desenvolvimento da pesquisa nesses campos, após um período de pouca efetiva interação. Na seção 2, considera-se a possibilidade de uma derivação minimalista ser tomada como modelo da computação conduzida em tempo real e problemas são apontados para esse tipo de identificação. Na seção 3, apresenta-se a proposta de um modelo misto (top-down/bottom up) da computação on-line no qual custo computacional possa ser, em princípio, associado à operação de movimento, distinguindo-se para isso, movimento com e sem custo computacional. A seção 4 traz uma síntese dos pontos levantados no artigo e aponta para direcionamentos futuros na construção de um modelo integrado da competência lingüística, no qual a proposta aqui apresentada venha a ser formalizada.

\section{A relação processador lingüístico-gramática em perspectiva}

Desde as primeiras formulações de um modelo da competência lingüística em termos de uma gramática gerativa com um componente transformacional até a concepção presente de língua interna no âmbito do Minimalismo, explicitar o modo como o conhecimento da língua e seu potencial produtivo, representados em uma gramática gerativa, são postos em uso, no processamento lingüístico, é um problema mal resolvido. Três diferentes momentos podem ser identificados no que concerne à relação processador-gramática, considerando-se o modo como Lingüística e Psicolingüística se relacionam ao longo do tempo: em estreita aproximação, em considerável distanciamento, com a possibilidade de integração. A seguir, cada um desses momentos será caracterizado.

\subsection{Uma estreita relação}

Na década de 60, quando a Psicolingüística começava a emergir no contexto da Psicologia Cognitiva em estreita relação com a Lingüística Gerativista (cf. Miller \& Chomsky, 1963), a possibilidade de uma deriva- 
ção gramatical dar origem a previsões acerca de demandas de processamento aferidas comportamentalmente foi seriamente considerada, no que ficou conhecido como Teoria da Complexidade Derivacional (TCD) (Miller \& McKean, 1964). A TCD, ainda que não assumisse uma identificação entre modelo de língua e de processamento lingüístico, atribuía um alto grau de correspondência entre as operações formais da gramática e processos mentais/cerebrais subjacentes à análise de enunciados lingüísticos, uma vez que demandas de processamento seriam função do número ou da complexidade de operações transformacionais, supostamente necessárias à derivação da sentença ${ }^{8}$.

O suporte inicial para a TCD foi obtido por meio de tarefas que solicitavam dos participantes o pareamento entre sentenças do tipo kernel (em Chomsky, 1957) e sentenças daquelas derivadas por meio de regras transformacionais tais como passivização, negativização, relativização, no modelo de então. Os participantes levavam mais tempo relacionando as sentenças cuja derivação requereria mais de uma transformação ou transformação mais complexa do que outra. Assim, uma sentença do tipo "Hasn't the paper been typed by the secretary?" apresentava maior demanda do que sentenças correspondentes derivadas por meio de apenas uma ou duas das três transformações naquela envolvidas. Resultados obtidos em tarefas de julgamento de valor verdade envolvendo passivas e negativas como em "treze não é precedido por sete" também foram apresentados em suporte à TCD (McMahon, 1963).

Após o entusiasmo inicial, ficou demonstrada a fragilidade da hipótese. A maçã verde não era menos palatável do que a maçã que é verde, por exemplo, como a teoria de então faria prever (cf. Fodor, Bever \& Garrett, 1974). A falta de sustentação empírica para a TCD deu margem à rejeição da idéia de se definir uma métrica da complexidade do processamento em função de operações caracterizadas em um modelo formal de gramática. $\mathrm{O}$ problema maior, contudo, poderia estar não na definição de uma métrica, mas na inadequação empírica do modelo de gramática de então, como

8. A hipótese é inspirada em considerações de Miller \& Chomsky (1963, p.481) com relação a um modelo algorítmico (finitary model) do "usuário da língua" (em princípio distinto de um modelo de gramática): "A plausibilidade psicológica de um modelo transformacional do usuário da língua seria obviamente fortalecida se pudesse ser demonstrado que nosso desempenho em tarefas que requerem uma apreciação da estrutura de sentenças que resultam de transformação é, em algum sentido, função da natureza, do número e da complexidade das transformações gramaticais envolvidas" (Tradução do autor (T.A.)). 
modelo cognitivo, inadequação esta que veio a ser constatada no próprio desenvolvimento da teoria lingüística, ante os critérios de validação empírica por esta estipulados - adequação descritiva aliada à adequação explantória (Chomsky, 1965). Assim sendo, diante dos desenvolvimentos recentes dessa teoria, a possibilidade de se tomar uma derivação lingüística como referência para hipóteses acerca de demandas de processamento vem sendo seriamente reconsiderada (cf. Phillips, 1996; Jakubowicz, 2003; 2006).

\subsection{Distanciamento e autonomia}

Em conseqüência da insatisfação com a TCD, observou-se, nas décadas subseqüentes, considerável distanciamento entre a Teoria Lingüística e a Psicolingüística. No âmbito da Lingüística, o gerativismo começava a se diversificar em termos de propostas e formalismos, que assumiram diferentes posicionamentos diante da questão da implementabilidade e da aprendibilidade do modelo. Em sua vertente tradicional (chomskyana), a pesquisa gerativista mantém sua ênfase na construção de uma teoria do estado inicial da aquisição da linguagem, com vistas a dar conta do problema da aprendibilidade, e não se ocupa com implementabilidade, seja em termos de tornar implementável um modelo da língua em estado virtual, seja em termos da caracterização de um algoritmo do usuário da língua, como originalmente proposto. Formalismos alternativos viriam a dar ênfase à implementabilidade computacional da gramática, não necessariamente enfocando o problema da aprendibilidade? .

O direcionamento tomado pelo PM parece sugerir, não obstante, que tratar de aprendibilidade independentemente da implementabilidade do modelo não é viável. Ainda que a questão da implementabilidade não seja enfocada diretamente, uma preocupação com a mesma norteia a proposta veiculada no $\mathrm{PM}$, visto que o resultado de uma derivação lingüística deve atender a condições de legibilidade nas interfaces entre o sistema da língua e sistemas que atuam no desempenho lingüístico.

9. Como exemplos de formalismos alternativos no contexto da Lingüística Gerativista tem-se, por exemplo, a LFG (Lexical Functional Grammar) (Bresnan, 1982, 2001); a HPSG (Head Driven Phrase-structure Grammar) (Pollard \& Sag, 1987, 1994), a IPG (Incremental Procedural Grammar) (Kempen \& Hoencamp, 1982, 1987) e a Tree-Adjoining Grammar (TAG) (Vijay-Shanker and Joshi, 1985). 
No âmbito da Psicolingüística, que se constituiu como campo autônomo, uma série de caminhos passa a ser explorada, a partir do abandono da TCD: a caracterização de procedimentos de parsing (análise sintática) operações mentais que resultam na construção de uma árvore sintática (marcador sintático), a partir de informação proveniente de uma seqüência de elementos do léxico (Kimball, 1973); o estudo do processamento do sinal acústico da fala (Eimas, 1974; Mehler, 1981); o estudo dos lapsos da fala na construção de modelos de produção de enunciados (Garrett, 1975; 1980; 2000; Dell, 1986), e a exploração do que veio a ser denominado Léxico Mental ${ }^{10}$ em função do modo como o conhecimento relativo a palavras/morfemas ou expressões cristalizadas, por parte do falante, pode ser acessado (Caramazza, Laudanna \& Romani, 1988; Levelt, Roelof \& Meyers, 2001).

No que concerne ao parsing, apenas a informação correspondente à "estrutura de superfície" da sentença, nos termos da época, daria origem a um marcador-frasal passível de ser semanticamente interpretado, ou seja, a interpretação semântica da sentença seria obtida sem que o reverso de operações transformacionais fosse requerido (Kimball, 1973). A análise conduzida pelo parser (aparato cognitivo responsável por esta tarefa) baseia-se em informação categorial, na presença de marcas de encaixamento (como conectivos ou justaposições de sintagmas como nas relativas sem pronome relativo do inglês), na ordenação de elementos do léxico/constituintes em função da ordem canônica da língua, e na presença de afixos, levando em conta as limitações do componente de curto-prazo da memória de trabalho operativa no processamento de sentenças. Especial atenção foi dada para problemas específicos de parsing, situações em que a análise sintática não pode ser resolvida exclusivamente com base em conhecimento gramatical, como os casos de ambigüidade estrutural ${ }^{11}$, ou em que a

\footnotetext{
10. Léxico Mental difere de Léxico, tal como concebido em um modelo de língua. Esse último apresenta-se como uma lista de elementos compostos por traços semânticos, fonológicos e formais, caracterizada formalmente de forma minimamente necessária à explicitação de operações gramaticais. O primeiro, por outro lado, refere-se a uma estrutura cognitiva cujas unidades, mantidas numa memória de longo prazo, e recuperadas na produção e na compreensão de enunciados verbais, podem estar relacionadas em função de suas propriedades semânticas, fonológicas e formais e ser susceptíveis a efeitos de fatores externos à língua (como freqüência de uso, representação escrita). No que concerne aos traços/propriedades semânticas, há controvérsia com relação ao quanto de informação de natureza pragmática e enciclopédica estaria disponível em representações lexicais.

11. Como exemplo de ambigüidade estrutural, tem-se Maria chamou a vizinha do terceiro andar, em que o PP sublinhado pode ser interpretado como modificador de vizinha ou como adjunto adverbial, vinculado a um nó mais alto da estrutura hierárquica.
} 
análise imediatamente conduzida pelo parser leva a erro, como no fenômeno do labirinto (garden path) ${ }^{12}$ (cf. Frazier, 1979, 1987; Frazier \& Clifton, 1996; Townsend \& Bever, 2002 para revisão de modelos). Princípios de parsing determinariam a solução mais imediata ou automática diante de uma ambigüidade estrutural, levando em conta informação de natureza configuracional (como relativa à altura de nós sintáticos no marcador-frasal em construção ou à necessidade de se construir novo nó), antes que informação externa à língua (como informação vinda do contexto de enunciação) viesse a contribuir para a solução do impasse. O fenômeno do labirinto, por sua vez, chamaria atenção para o predomínio do papel de informação de natureza argumental e relativa à grade temática de verbos ditando as decisões imediatas do parser $^{13}$. O papel da prosódia, delimitando unidades de processamento, viria a ser mais tarde explorado, seja na percepção da fala, ou de forma implícita na leitura (Fodor, 1998, 2005), compondo um quadro no qual a informação passível de ser obtida a partir do modo como o enunciado lingüístico se apresenta ao processador lingüístico, numa dada janela de processamento ${ }^{14}$, possibilita a condução automática da análise sintática de sentenças e a interpretação semântica desta dependente. Em outras palavras, a pesquisa psicolingüística sugere que o parser opera com base em informação gramatical que se faz legível na seqüência de elementos do léxico reconhecida a partir do processamento do material acústico da fala (ou de sua representação gráfica na escrita), tal como recortado em unidades prosódicas.

Quanto ao processamento do sinal acústico da fala, este passou a ser focalizado tanto na perspectiva do adulto, que possui conhecimento do léxico da língua, quanto na perspectiva de infantes, que têm acesso à lín-

12. Como exemplo de labirinto (garden-path), tem-se Maria contou ao irmão que vai para a Babia a novidade, na qual, na ausência de pistas prosódicas, a oração sublinhada é imediatamente analisada como completiva, análise esta que se mostra inadequada no momento em que o constituinte $a$ novidade é encontrado e não pode ser analisado como complemento do verbo contar. Conseqüentemente, a análise tem de ser refeita explorando-se a possibilidade estrutural de a oração introduzida por que ser analisada como relativa.

13. No exemplo da nota anterior, observa-se que a análise privilegiada para a oração sublinhada é a de oração completiva, satisfazendo aos requerimentos do verbo contar da sentença matriz, e não a de oração relativa, que tem função de adjunto.

14. Entende-se por janela de processamento a seqüência de elementos que pode ser mantida ativada nos limites de tempo do componente de curto prazo da memória de trabalho. 
gua por meio do som da fala (ou correlato $)^{15}$ e precisam delimitar unidades correspondentes a classes de elementos do léxico, de modo a conduzir uma análise que resulte na identificação da gramática da mesma (Mehler et al., 1981; Eimas, 1996; Morgan \& Demuth, 1996; Jusczyk, 1997). Assim sendo, o problema da aquisição de uma língua materna formulado, no âmbito da teoria lingüística, em função da possibilidade de múltiplas relações estruturais serem estabelecidas a partir de uma seqüência de elementos do léxico, é abordado, no âmbito da pesquisa psicolingüística, a partir da delimitação de unidades prosódicas, que podem facilitar a delimitação de unidades sintagmáticas e da identificação de padrões recorrentes na fala. Esse tipo de abordagem chama atenção para a importância da percepção do que há de sistemático da língua, que se manifesta em padrões distribucionais, identificados em unidades que podem corresponder a unidades sintáticas. Dessa forma, a detecção de elementos de classes fechadas (elementos funcionais) e o reconhecimento de sua distribuição em relação aos de classe aberta mostram-se fundamentais para que se dê início ao parsing do material lingüístico pela criança e a busca de distinções semânticas correspondentes a alterações de forma no âmbito dos primeiros - cruciais para a identificação da morfologia da língua (cf. Corrêa, 2007; a sair).

No que diz respeito à produção, o modelo concebido por Garrett (1975; 2000) e até hoje influente, caracteriza-se como um modelo serial, feed forward, que supõe etapas distintas para o estabelecimento de relações hierárquicas, para a inserção de afixos (anteriormente às raízes a que estes se acoplam) e ordenação linear dos constituintes assim estruturados, a qual precederia a codificação morfofonológica necessária a um planejamento articulatório. De forma análoga, no modelo de produção de Levelt (1989; 1995) e Bock \& Levelt (1994), a codificação gramatical envolve o que é chamado de processamento funcional e processamento posicional. O primeiro daria origem à atribuição de caso/funções sintáticas e seria determinado basicamente a partir da estrutura argumental de verbos. Um posicionamento básico dos argumentos do verbo poderia ser determinado nesse ponto. No processamento posicional seriam especificadas as flexões e a ordenação linear dos constituintes que precede a codificação morfofonológica. Nesse modelo, a formulação sintática se faz com base na informação gramatical

15. Ver nota 1. 
codificada nos lemas $^{16}$ dos elementos recuperados do léxico em função de suas propriedades semânticas a partir da concepção de uma mensagem ${ }^{17}$. A codificação morfofonológica, posterior à formulação sintática, envolveria acesso aos lexemas ${ }^{18}$ ou representações fonológicas associadas aos lemas.

É interessante observar que desde a proposta de Garrett (1980), uma distinção fundamental é feita entre elementos de classe aberta e classe fechada, com base no modo como estes se comportam na produção da fala. Esses últimos são pouco vulneráveis aos erros característicos dos membros de classes abertas (substituições, interpolações, aglutinações), mesmo quando sua freqüência é controlada e são particularmente omitidos por afásicos. Elementos de classe fechada definiriam, nos modelos de produção aqui considerados, um esquema sintático básico (frame) no qual elementos de classe aberta seriam inseridos. Esse tipo de distinção, aliada ao tipo de informação gramatical codificada nesses elementos, servirá de base para a proposta aqui encaminhada para o tratamento do problema da direcionalidade da computação lingüística numa tentativa de unificação processador-gramática.

A dissociação entre representações concernentes a propriedades semânticas/formais e a propriedades fonológicas dos elementos do léxico mostra-se necessária em função dos resultados da pesquisa sobre o Léxico Mental. Propriedades semânticas de elementos do léxico advém da interação entre a língua e uma cognição mais ampla (diferentes estruturas conceptuais, tais como, memória semântica, conhecimento enciclopédico, assim como com sistemas de crenças e conhecimento relativo aos contextos em que o uso de determinadas formas mostra-se apropriado), enquanto que as representações de natureza fonológica, correspondem a abstrações de propriedades físicas (acústicas) dos sons da fala ou de propriedades do trato

16. Entende-se por lema a representação das propriedades gramaticais vinculadas ao que seria o significado de uma palavra/morfema por meio da qual entidades conceptuais e lexicais se relacionam

17. O termo mensagem não parece ser o mais adequado, pois sugere ser necessariamente parte da intenção de fala do falante comunicar a outrem um conteúdo proposicional, quando suas motivações podem ser distintas ao produzir a fala. O termo é, não obstante, usado em modelos psicolingüísticos da produção e, por isso, é aqui recuperado.

18. Lexema nomeia, em modelos psicolingüísticos, a representação fonológica correspondente ao complexo propriedades semânticas/lema, cujo acesso é independente daquele e sujeito a efeito de freqüência. 
vocal, quando da articulação dos mesmos, e são particularmente susceptíveis a efeitos de freqüência. O quanto o Léxico Mental pode ser concebido como parte de um domínio lingüístico ou domínio compartilhado por uma cognição mais geral é uma questão não satisfatoriamente resolvida. De qualquer forma, em modelos como os de Levelt, os lemas apresentam-se como elementos do léxico de natureza especificamente lingüística sobre os quais atua o formulador sintático e, de forma análoga, o parser.

A necessidade de se supor uma gramática que determine as ações do formulador sintático e do parser sobre lemas correspondentes às palavras/ morfemas recuperados do léxico na produção/compreensão de enunciados é, em geral, assumida no contexto da pesquisa psicolingüística ${ }^{19}$. Não há, contudo, consenso quanto ao tipo de formalismo lingüístico que seria empiricamente adequado para a caracterização dessas ações. $\mathrm{O}$ tipo de modelo de gramática veiculado pela teoria dos Princípios e Parâmetros (P\&P) dos anos 80 (Chomsky, 1981; 1986) serviu de base para algumas propostas de modelos de parsing (Weinberg \& Berwick, 1984; Gorell, 1995), ainda que um algoritmo suficientemente explícito do modo como a gramática alimentaria as ações do parser não tenha sido formulado. No que concerne à produção, as ações do formulador sintático não são usualmente expressas de forma suficientemente clara. Esquemas ilustrativos são apresentados, ainda que um algoritmo de implementação seja raramente explicitado (cf. Bock \& Levelt, 1994; Viggliocco \& Nicol, 1998). Quando o é, formalismos alternativos à vertente tradicional do gerativismo são particularmente explorados, como a $\mathrm{TAG}^{20}$, que incorpora, no léxico, árvores primitivas, eliminando, desse modo, a necessidade de se postularem operações de movimento com vistas a posicionar constituintes em sua ordem canônica (cf. Ferreira, 2000).

Em suma, os desenvolvimentos da pesquisa psicolingüística que sucederam o abandono da proposta da TCD sugerem que toda a informação necessária para a formulação de enunciados encontra-se representada no léxico, especificamente nos lemas sobre os quais operações sintáticas se rea-

19. Essa assunção está necessariamente presente em modelos de natureza estrutural. Em modelos de natureza probabilística e no contexto do paradigma conexionista, relações gramaticais são subproduto de relações que se estabelecem de forma, a princípio aleatória, e que passam a ganhar diferentes pesos ao longo do tempo em função da probabilidade com que se estabelecem em determinados contextos.

20. Ver nota 6. 
lizam. O resultado da formulação sintática na produção é linearizado, de acordo com a ordenação canônica da língua e fatores pertinentes às condições específicas do discurso (como definição/alteração de tópico, foco informacional, preferência por elementos animados em posição de sujeito, dentre outros). No que concerne à compreensão, toda a informação necessária para a análise e interpretação semântica de uma expressão lingüística encontra-se expressa no modo como o enunciado lingüístico se apresenta à segmentação, ao acesso lexical e ao parser. Este recorre ao conhecimento de uma ordenação canônica (não marcada), assim como ao posicionamento de elementos de natureza funcional (conectivos e afixos, por exemplo) como referência para a análise. Os princípios que guiam as ações do parser garantem a satisfação imediata dos argumentos requeridos pelo verbo, a opção imediata pela análise mais simples, e atendem a restrições impostas pelo componente de curto-prazo da memória de trabalho.

Princípios que atendem a restrições impostas pelos sistemas que atuam no desempenho lingüístico viriam a ser assumidos como aqueles que restringem a forma das gramáticas das línguas humanas no PM. O fato de as gramáticas obedecerem a restrições impostas pela arquitetura e modo de funcionamento de todo o aparato que atua no processamento de enunciados lingüísticos viabilizaria, então, a idéia de unificação processador lingüístico / gramática no contexto do PM?

\subsection{Convergências: derivação minimalista e modelos de processamento}

A década de 90 inaugura uma nova fase da pesquisa lingüística na qual se observam direcionamentos que vão ao encontro de resultados da pesquisa psicolingüística que se havia desenvolvido de forma, em grande parte, independente, nas duas décadas precedentes. Essa fase tem suas diretrizes programáticas explicitadas no Programa Minimalista (PM) $(\text { Chomsky, 1995a })^{21}$. Apresenta-se a seguir uma caracterização sintética da

21. Chomsky (2005) afirma que não há descontinuidade na trajetória da teoria que resulta no PM. Certamente, o PM é coerente com as propostas iniciais do gerativismo e dá continuidade à concepção de aquisição de uma língua em termos de fixação do valor de parâmetros de variação, dados princípios universais, e à idéia de que a variação paramétrica estaria restrita ao léxico, mais especificamente às propriedades de núcleos funcionais (Borer, 1984) A principal diferença entre a proposta do PM e estados anteriores da teoria reside no fato de que, enquanto naqueles os 
proposta veiculada no PM e seus desdobramentos (Chomsky, 1998; 1999; 2001; 2005; Hauser, Chomsky \& Fitch, 2002), de modo que essa convergência possa ser evidenciada ${ }^{22}$.

No PM, enfatiza-se o fato de língua poder ser concebida como parte do mundo natural, ou seja, como algo que se realiza em decorrência de condições biológicas específicas da espécie humana. Nesse sentido, entende-se que a natureza humana provê uma faculdade de linguagem (FL), concebida como um leque de capacidades que viabilizam a constituição de línguas (sistemas que possibilitam que se relacione um conteúdo proposicional a um meio físico). Assim sendo, FL, entendida em sentido amplo, inclui uma língua I (língua interna, ou simplesmente língua), constituída de um sistema computacional universal e de um léxico, adquirido no curso da aquisição da linguagem, assim como inclui ou pressupõe todos os sistemas recrutados para o desempenho lingüístico - os sistemas que atuam, por um lado, na percepção e na articulação da fala e, por outro, na concepção e integração de um conteúdo proposicional vinculado a um estado mental responsável por uma intenção de fala (os chamados sistemas perceptual/ articulatório e conceptual/intencional). Memória, sistema respiratório, circulatório, dentre outros, provém suporte para que FL em sentido amplo se realize no uso da língua. Em sentido restrito, FL corresponde ao sistema computacional da língua (sintaxe restrita) - conjunto mínimo de operações computacionais $^{23}$ que constroem objetos sintáticos a partir de elementos do léxico na derivação de expressões lingüísticas, possivelmente desenvol-

princípios de parâmetros de GU eram concebidos de forma não motivada (como especificamente lingüísticos), no PM estes são vistos como decorrentes de imposições das interfaces. Esta diferença representa, a nosso ver, uma descontinuidade fundamental na trajetória da teoria, tornando-a mais compatível com desenvolvimentos em outros domínios das ciências cognitivas.

22. Fazemos referência ao programa minimalista apresentado em (Chomsky, 1995a), particularmente no cap. 4 e desdobramentos posteriores. Não consideramos que haja um, ou mais, "modelos" minimalistas a serem referidos. A proposta ainda se apresenta de forma programática visto que conceitos fundamentais ainda se encontram em processo de definição. Assim sendo, tomamos a concepção minimalista que pode ser depreendida da literatura referida, sem nos atermos a soluções formais específicas propostas em um ou outro ponto da trajetória do programa, a menos que isso se mostre essencial para a argumentação.

23. As operações computacionais apresentadas em Chomsky (1995a) são Select, Merge, Agree e Move. Em trabalhos posteriores Move é redefinido como Merge+Copy (Chomsky,1995b; Bobaljik, 1995) e como Merge externo, em contraste com Merge interno (originalmente Merge) (2001). Num primeiro momento da proposta minimalista, à operação Move é associado maior custo computacional. Já Merge interno e externo se distinguem em termos de necessidades sintáticas decorrentes da estrutura argumental, no caso de Merge interno, ou de requisitos de ordem discursiva, no caso de 
vido de forma independente dos demais sistemas que constituem FL em sentido amplo. ${ }^{24}$ Expressões lingüísticas são concebidas como pares (Forma Fonética (Phonetic form - PF), Forma Lógica (Logical Form - LF)) que se apresentam como níveis representacionais que estabelecem interface entre a língua e os demais sistemas de FL responsáveis pelo desempenho lingüístico. Lingua é, portanto, entendida como um sistema cognitivo que tem a possibilidade de interlocução como propriedade inerente à sua constituição.

A computação sintática parte de uma numeração/arranjo lexical (ou sub-arranjo), ou seja, de um dado conjunto de elementos do léxico. ${ }^{25} \mathrm{O}$ léxico é constituído de unidades matriciais compostas por traços semânticos, fonológicos e formais. Os primeiros podem ser interpretados na interface semântica (LF). Os segundos fornecem informação a ser codificada na interface fônica $(\mathrm{PF})$. Os terceiros são instrumentais para a computação sintática e caracterizam-se como interpretáveis e não-interpretáveis. Os traços formais semanticamente interpretáveis representam propriedades provenientes de distinções semânticas que se mostram gramaticalmente relevantes numa dada língua ${ }^{26}$. Os traços não-interpretáveis são postula-

Merge externo, e são tratados de forma semelhante no que diz respeito a economia. Neste artigo, os termos Merge e Move são usados independentemente do ponto de desenvolvimento da teoria, assumimos que as operações correspondentes se distinguem em termos de necessidades sintáticas e mantemos a idéia de que Move (ou Merge externo) acarreta maior custo computacional (a menos que fatores pertinentes ao processamento de sentenças no discurso venham a alterá-lo).

24. Ver nota 7.

25. A idéia comum aos conceitos de numeração, arranjo lexical (lexical array) e sub-arranjo é a de que o léxico não é continuamente acessado durante uma derivação lingüística. A derivação parte de um "seleção" inicial de elementos do léxico e nada mais é introduzido a partir de então. A diferença entre numeração (Chomsky, 1995a) e arranjo lexical (Chomsky, 1998) é estritamente formal - numeração pode ser entendida como um arranjo lexical no qual os elementos do léxico são indexados de forma a indicar o número de vezes que cada um deverá entrar na derivação (a derivação termina quando todos os índices são zerados). Com a introdução do conceito de fase como unidade da computação sintática (Chomsky, 1999), introduz-se também o conceito de sub-arranjo, cada qual contendo os elementos que compõem uma fase. Neste artigo, tratamos numeração, arranjo ou sub-arranjo, de forma indiferenciada.

26. Algumas distinções semânticas parecem ser universalmente tomadas como gramaticalmente relevantes. Outras estariam restritas a particulares conjuntos de línguas. Línguas podem, em princípio, variar quanto às distinções semânticas passíveis de serem tomadas como gramaticalmente relevantes, nos limites das distinções factíveis pelo aparato cognitivo humano. Distinções gramaticalmente relevantes podem ser identificadas no que há de sistemático na língua - padrões regulares na interface fônica indicativos de elementos funcionais, de afixos flexionais assim como de relações sintáticas expressas na ordenação canônica dos constituintes. Com isso, os traços formais adquirem relativa autonomia com relação às distinções semânticas originais, como se observa com gênero e número intrínsecos e com a possível dissociação entre pessoa gramatical e do discurso. 
dos para que a computação sintática possa ser implementada exclusivamente a partir de informação codificada no léxico e são eliminados ou valorados no curso da computação, de modo que apenas traços legíveis nas interfaces fonética e semântica estejam presentes ao fim da mesma. O léxico tem, portanto, representadas, nos traços formais, "instruções" a serem seguidas pelo sistema computacional na derivação de uma expressão lingüística, as quais representam conhecimento adquirido no curso da aquisição da língua em questão, em função da fixação do valor dos parâmetros de variação previsíveis no estado inicial da aquisição da língua $(\mathrm{GU})^{27}$.

O sistema computacional da língua reconhece e opera exclusivamente sobre traços formais. Estes podem ser entendidos como representação no léxico, daquilo que é identificado a partir do reconhecimento de padrões sistemáticos na aquisição da língua e de alterações sistemáticas seja na ordem linear ou no âmbito de elementos de calasse fechada (Correa, 2007; a sair). O algoritmo que implementa a computação lingüística encontrase, desse modo, definido pelas operações do sistema computacional, pela informação codificada nos traços formais dos elementos que constituem a numeração/arranjo lexical.

A derivação é conduzida a partir da seleção de um elemento da numeração/arranjo lexical - um núcleo cujos requisitos são satisfeitos por meio de Merges sucessivos ${ }^{28}$. Os núcleos (lexicais e funcionais) com requisitos a serem satisfeitos ${ }^{29}$ entram na derivação como uma projeção mínima e têm

27. A previsibilidade quanto ao que se constitui como parâmetro de variação advém do fato de as distinções semânticas que possam vir a ser tomadas como propriedades de traços formais de uma dada língua serem restringidas pelas possibilidades discriminatórias da cognição humana, enquanto que as distinções pertinentes à expressão de relações sintáticas na interface fônica são restringidas pelas propriedades físicas do trato vocal ou aparato físico alternativo.

28. O modo de operação do algoritmo gerativo não se encontra claramente explicitado. O verbo parece ter prioridade na derivação uma vez que é o tipo de predicador que, juntamente com seus argumentos (interno (objeto lógico) e externo (sujeito lógico)), pode entrar em correspondência com um conteúdo proposicional. Uma derivação ascendente parte, não obstante, do elemento mais profundamente encaixado, como o complemento de preposição ou de verbo (de uma oração principal ou encaixada à direita), e nada informa (em termos de traços formais) ao sistema computacional quais seriam os primeiros elementos a serem selecionados da numeração/arranjo lexical.

29. Núcleos lexicais apresentam requisitos categoriais e temáticos a serem satisfeitos computacionalmente enquanto que núcleos funcionais apresentam apenas os primeiros. Não é claro, no entanto, de que modo informação temática seria reconhecida pelo sistema computacional que opera exclusivamente sobre traços formais. Uma solução (a mais imediata, embora ad hoc) seria tomar 
seus traços projetados nos nós formados de forma ascendente (bottom-up) na estrutura hierárquica criada por meio de Merge. Os elementos que satisfazem a esses requisitos entram na derivação como projeções máximas ou míni/maxi, como os pronomes ${ }^{30}$.

Qualquer que seja a língua, o primeiro merging resulta no posicionamento do complemento à direita do núcleo, em relação de irmandade com este, e no posicionamento do especificador à esquerda do nó decorrente da concatenação entre núcleo e complemento - uma projeção intermediária sendo ambos dominados pela projeção máxima do núcleo. A estrutura hierárquica resultante constitui uma unidade de c-comando, assumido como assimétrico (o especificador c-comanda os constituintes subordinados ao nó que o domina e o contrário não é verdadeiro) (Kayne, 1994). Esta estrutura define o que seria uma ordem universal (SVO ou Espec, Núcleo, Complemento $)^{31}$ assim como o domínio no qual Agree promove o pareamento de elementos que compartilham traços de mesmo tipo (os chamados traços $p h i$ - gênero, número e pessoa) e a valoração da contraparte não interpretável pelo valor do membro interpretável do par (Chomsky, 1999).

Uma vez que línguas variam no modo como relações sintáticas se fazem visíveis na interface fônica, o modelo explicita a relação entre "ordenação inicial" ou universal, ordenação canônica em uma dada língua e as possibilidades de alteração dessa ordem nas línguas, em função do valor assumido por parâmetros de variação. O sistema computacional é infor-

papel temático como traço formal, como sugerido por Hornstein (2001), no tratamento de estruturas de controle, e incorporada em Adger, 2003. Essas lacunas com relação ao modo de implementação do algoritmo da computação lingüística em função de informação codificada no léxico serão aqui ignoradas para que a argumentação proceda.

30. O PM assume a hipótese da bare phrase structure segundo a qual a natureza da projeção mínima ou máxima - de um elemento do léxico é definida relacionalmente na computação sintática e não no léxico, como em momentos anteriores da teoria.

31. A idéia de uma "ordem universal" parece encontrar suporte empírico em dados da aquisição de línguas de morfologia rica, antes que morfemas de caso sejam sistematicamente utilizados, na produção de afásicos, assim como na ordenação default em línguas não configuracionais (Slobin, 1966; Platzack, 1988; Christianson \& Ferreira, 2005). Não é claro, contudo, o que justificaria uma ordem universal SVO, uma vez que ordenação parece ser uma imposição do meio físico de realização da fala no tempo. Fatores como proeminência do elemento animado, mais comumente assumindo a função de agente e experenciador (cf. McDonald, Bock, \& Kelly, 1993) talvez possam prover uma motivação cognitiva (anterior à língua) para a ordenação tomada como básica. Fatores de ordem fônica poderiam, por sua vez, explicar a alteração da mesma. A sugestão de Chomsky (1999) para que movimento de núcleo seja tratado em PF e não na sintaxe é compatível com essas considerações 
mado da necessidade de mover núcleos ou DPs de seu sítio de origem, pela presença de um traço formal não interpretável (EPP) ${ }^{32}$ em determinado núcleo $(\mathrm{C}, \mathrm{T}$ ou $v$ ), e da necessidade de mover elementos de sua posição canônica pelo valor assumido por traços pertinentes à força ilocucionária, focalização, dentre outros. A presença de um traço EPP implica que uma posição de especificador seja criada para a qual constituintes devem ser movidos $^{33}$. Dada essa informação, a operação Move desloca elementos da posição em que foram gerados por Merge (externo), para sua posição canônica na língua, ou dessa posição para uma posição marcada, na periferia esquerda, por exemplo.

O movimento de constituintes e de núcleos ${ }^{34}$ para posições estruturais específicas determina a ordenação dos mesmos na interface fonética, uma vez que o modelo incorpora o Axioma da Correspondência Linear (ACL), segundo o qual posições estruturais em uma relação de c-comando assimétrico definem a ordem em que constituintes se apresentam em enunciados lingüísticos (o especificador precede o núcleo que, por sua vez, precede o complemento) (cf. Hornstein, Nunes \& Grohmann, 2005).

Concluída a computação sintática, seu resultado - uma estrutura hierárquica -, é spelled out e a derivação prossegue de forma bifurcada. Por um lado, a informação codificada em traços fonológicos e a informação relativa ao posicionamento hierárquico dos nós que os contém será computada de modo a dar origem a uma seqüência linearmente ordenada de elementos do léxico, apresentada por meio de suas propriedades fonéticas (PF). Por outro lado, a informação codificada em traços semânticos e o posicionamento hierárquico dos nós que os contém definem relações semânticas, expressas em termos proposicionais em $\mathrm{LF}^{35}$.

\footnotetext{
32. EPP, sigla originária do Extended Projection Principle de momento anterior da teoria, caracteriza como traço do léxico informação relativa à ordenação de constituintes. Trata-se de um recurso formal que desempenha neste modelo papel semelhante ao de esquemas (frames), ou árvores primitivas, em modelos alternativos.

33. A satisfação do traço EPP também pode se dar pelo Merge de um expletivo, como em It rains.

34. O movimento de núcleo não é satisfatoriamente caracterizado no modelo de língua. Inicialmente associado aos chamados traços fortes, deixou de ter caracterização clara uma vez que essa categoria foi eliminada. Ver nota 26.

35. As operações necessárias à transformação da informação proveniente de traços fonológicos (e da prosódia) em informação fonética e o modo como afixos flexionais que resultam da operação de concordância são inseridos de forma a se realizarem na interface fônica não são explicitadas no PM, assim como não o são as operações que codificam informação semântica em LF.
} 
Uma vez que PF e LF constituem níveis de interface, a informação codificada em PF permite que expressões lingüísticas sejam convertidas em um meio físico, por parte de um sistema articulatório, na produção da fala, assim como permite que o continuum de sons da fala seja segmentado em unidades correspondentes à forma fônica de elementos do léxico, na compreensão. A informação codificada em LF, por sua vez, corresponde a uma proposição (ou parte desta), passível de ser semanticamente interpretada.

Derivações convergentes são aquelas que resultam em informação legível nas interfaces fônica e semântica, uma vez que, de acordo com a proposta do PM, a forma das línguas humanas é restringida pelo Princípio da Interpretabilidade Plena (PIP) que, juntamente com condições gerais de economia, atende às imposições das interfaces. Ou seja, para que uma derivação lingüística convirja, esta tem de transcorrer de forma a minimizar custo computacional e seu resultado tem de ser legível pelo aparato fonador (ou substituto) / sistema auditivo (ou visual) humano e passível de ser semanticamente interpretável em termos compatíveis com a cognição humana - em termos de uma proposição. Para isso, as estruturas criadas por Merge possibilitam o estabelecimento de relações locais (em unidades de ccomando), definidas em função das propriedades dos traços formais dos elementos selecionados, e a computação é realizada ciclicamente por fases, delimitadas em função de unidades semanticamente completas. Em outras palavras, o PIP expressa a idéia de que as restrições que se impõem à forma das línguas humanas advêm da arquitetura do aparato que viabiliza o processamento lingüístico - cognição não lingüística, aparato fonador, memória, dentre outros -, idéia essa que havia sido expressa ainda na década de 70 no âmbito da pesquisa psicolingüística e que se encontra subjacente à pesquisa em aquisição da linguagem nesse contexto ${ }^{36}$.

Uma série de paralelos pode ser estabelecida entre a concepção de derivação lingüística no minimalismo e modelos de processamento de natureza estrutural e serial (Ver quadros 1 e 2 a seguir) $)^{37}$.

36. Para maior desenvolvimento desse ponto, ver Corrêa (2005b; 2006a; a sair).

37. Os esquemas apresentados tomam como referência modelos de processamento de natureza simbólica, serial, com componentes modulares, feed-forward, no caso da produção (Garrett, 1980; Levelt, 1989; 1995; Bock \& Levelt, 1994) e compatíveis com teorias de garden-parth e construal, com reanálise final, no caso do parsing (Frazier, 1979, 1987; Frazier \& Clifton, 1996). Admite-se, não obstante, que os limites das unidades de processamento sintático (modular) possam ser estabelecidos em unidades menores do que oração (DP tópico/sujeito, em línguas SVO, por exemplo). 


\begin{tabular}{|c|c|c|}
\hline \multicolumn{2}{|r|}{ Produção } & \multirow{2}{*}{$\begin{array}{l}\text { Derivação } \\
\text { Atuação do Princípio da Interpretabilidade Plena } \\
\text { restringindo a aleatoriedade na constituição da } \\
\text { numeração/arranjo lexical/subarranjo dada a } \\
\text { interação da língua com "sistemas de } \\
\text { desempenho" }\end{array}$} \\
\hline 1 & $\begin{array}{l}\text { Intenção de fala / conceptualização de } \\
\text { uma mensagem (equivalente a uma } \\
\text { proposição, a um tópico, ou argumento de } \\
\text { proposição) }\end{array}$ & \\
\hline 2 & $\begin{array}{l}\text { Acesso a elementos do Léxico Mental } \\
\text { cujos traços semânticos permitam } \\
\text { expressar aspectos pertinentes à intenção } \\
\text { de fala e ao conteúdo proposicional } \\
\text { (completo ou parcial) ou ao tópico da } \\
\text { mensagem }\end{array}$ & $\begin{array}{l}\text { Constituição da numeração/subarranjos a partir } \\
\text { de elementos recuperados do léxico (matrizes } \\
\text { constituídas por traços semânticos, fonológicos } \\
\text { e formais) }\end{array}$ \\
\hline 3 & $\begin{array}{l}\text { Acesso aos lemas correspondentes aos } \\
\text { elementos cujos traços semânticos foram } \\
\text { recuperados }\end{array}$ & Traços formais ativados \\
\hline 4 & $\begin{array}{l}\text { Formulação sintática ou codificação } \\
\text { gramatical (montagem de uma estrutura } \\
\text { hierárquica) de modo incremental }\end{array}$ & Computação sintática (em fases) \\
\hline 5 & $\begin{array}{l}\text { Linearização (posicionamento dos } \\
\text { constituintes hierarquicamente } \\
\text { relacionados) }\end{array}$ & $\begin{array}{l}\text { Spell out por fase (via fonológica) - } \\
\text { estabelecimento de correspondência entre } \\
\text { elementos em relação de c-comando e ordem } \\
\text { linear na interface fônica }\end{array}$ \\
\hline 6 & $\begin{array}{l}\text { Recuperação de lexemas e codificação } \\
\text { morfo-fonológica }\end{array}$ & $\begin{array}{l}\text { Operações fonológicas sobre os traços } \\
\text { fonológicos ativados (e toda informação } \\
\text { passível de ser codificada na interface fônica, } \\
\text { como informação prosódica), que resultam em } \\
\text { PF }\end{array}$ \\
\hline 7 & Planejamento articulatório & $\begin{array}{l}\text { Relações de interface entre a interface fônica e } \\
\text { sistemas responsáveis pela articulação do } \\
\text { enunciado codificado em PF }\end{array}$ \\
\hline 8 & $\begin{array}{l}\text { Produção efetiva do enunciado em sons } \\
\text { vocais (ou meio físico alternativo) }\end{array}$ & \\
\hline
\end{tabular}

Quadro 1: Paralelo entre os passos da produção de um enunciado lingüístico de acordo com modelos lineares, feed-forward e derivação minimalista.

Observa-se nos quadros 1 e 2 que os processos de produção e de compreensão incluem momentos anteriores à computação sintática sobre os quais um modelo de gramática nada tem a informar. A constituição da numeração/arranjo lexical, tomada como primitivo em um modelo formal de língua, corresponderia ao processo por meio do qual unidades com propriedades semânticas, vinculadas a um lema (representação equivalente a um conjunto de traços formais) e propriedades fonológicas (lexema) são recuperadas do Léxico Mental ${ }^{38}$ e mantidas ativadas na memória de

38. Ver nota 4. 
trabalho ${ }^{39}$. Note-se, nesse ponto, que, do ponto de vista de um modelo formal de língua, a constituição de uma numeração/arranjo lexical é aleatória. Assim sendo, apenas um pequeno subconjunto de todos arranjos passíveis de serem constituídos a partir de um léxico com um número $x$ de elementos pode dar origem a sentenças da língua. Este equivale ao subconjunto constituído pelos arranjos lexicais que podem entrar em correspondência com um conteúdo proposicional. Assumindo-se o PIP, contudo, a numeração/arranjo lexical tomada como ponto de partida de uma deri-

\begin{tabular}{|c|c|c|}
\hline \multicolumn{2}{|r|}{ Compreensão } & \multirow{2}{*}{$\begin{array}{l}\text { Derivação } \\
\text { Atuação do Princípio de interpretação Plena } \\
\text { restringindo a aleatoriedade na constituição da } \\
\text { numeração/arranjo lexical/subarranjo dada a } \\
\text { interação da língua com "sistemas de } \\
\text { desempenho" }\end{array}$} \\
\hline 1 & $\begin{array}{l}\text { Processamento do sinal acústico da fala, } \\
\text { delimitação de unidades prosódicas e } \\
\text { reconhecimento de lexemas (forma fônica } \\
\text { de elementos do léxico) }\end{array}$ & \\
\hline 2 & $\begin{array}{l}\text { Acesso aos lemas (e grade temática dos } \\
\text { predicadores) correspondentes a lexemas } \\
\text { seqüencialmente ordenados numa unidade } \\
\text { prosódica /sintática }\end{array}$ & $\begin{array}{l}\text { Constituição da numeração/subarranjos a partir } \\
\text { de elementos recuperados do léxico (matrizes } \\
\text { constituídas por traços semânticos, fonológicos } \\
\text { e formais) }\end{array}$ \\
\hline 3 & $\begin{array}{l}\text { Condução do parsing a partir da } \\
\text { informação codificada nos lemas } \\
\text { (montagem de uma estrutura hierárquica) }\end{array}$ & Computação sintática (em fases) \\
\hline 6 & $\begin{array}{l}\text { Interpretação semântica da estrutura } \\
\text { sintática resultante do parsing }\end{array}$ & $\begin{array}{l}\text { Spell out por fases (via semântica) - ativação } \\
\text { dos traços semânticos e operações semânticas } \\
\text { que mapeiam relações sintáticas em relações } \\
\text { de natureza proposicional, as quais resultam em } \\
\text { LF }\end{array}$ \\
\hline 7 & $\begin{array}{l}\text { Recuperação de "conhecimento de mundo" } \\
\text { e processos integrativos para atribuição de } \\
\text { sentido ao enunciado e vinculação do } \\
\text { mesmo ao contexto de enunciação }\end{array}$ & $\begin{array}{l}\text { Relações de interface entre o sistema da língua } \\
\text { e sistemas conceptuais e intencionais }\end{array}$ \\
\hline 8 & Compreensão efetiva do enunciado & \\
\hline
\end{tabular}

Quadro 2: Paralelo entre os passos da compreensão de enunciados lingüísticos de acordo com modelos lineares que incorporam um parser que atua de forma modular em unidades sintáticas e derivação minimalista.

39. O paralelo entre os elementos presentes na numeração/arranjo lexical e aqueles ativados na memória de trabalho quando do início da formulação sintática não é total, visto que, enquanto os elementos que constituem a numeração/arranjo lexical incluem traços formais, fonológicos e semânticos a serem utilizados em diferentes momentos da derivação, em modelos de processamento lingüístico, o acesso aos lexemas (representação fonológica) é posterior ao acesso aos lemas (propriedades gramaticais) na produção, i.e. após a formulação sintática, e anterior na compreensão, possibilitando o reconhecimento lexical que daria acesso aos lemas. De qualquer forma, o fato de os traços fonológicos só serem utilizados na derivação lingüística pós Spell-out permite que um tipo de paralelismo seja estabelecido. 
vação lingüística tem de admitir essa correspondência (do contrário, o resultado da derivação não seria legível na interface semântica). $O$ modo como esse o arranjo inicial seria constituído não é, contudo, objeto da teoria lingüística. Em uma teoria que integre conhecimento e uso da língua, esse ponto é, no entanto, crucial, uma vez que, num modelo de produção, os elementos recuperados do léxico dão forma a uma intenção de fala e ao conteúdo de uma mensagem, e, num modelo de compreensão, a existência de uma intenção de fala e de uma mensagem é pressuposta pelo ouvinte, muito antes de este ter identificado a gramática da língua, como demonstram resultados experimentais com crianças de tenra idade (Macnamara, 1977; Hirsh-Pasek et al., 2006).

A computação sintática, explicitada numa derivação lingüística, corresponderia, por um lado, à formulação (ou codificação gramatical) de enunciados na produção, e por outro, ao parsing de enunciados lingüísticos na compreensão. Note-se que, uma vez que o sistema computacional atua sobre os traços formais do léxico (equivalentes a lemas), o mesmo algoritmo gerador de estruturas hierárquicas pode ser, em princípio, tomado como o formulador (atuando sobre os lemas recuperados em função de uma intenção de fala/concepção de mensagem na produção), e como o parser (atuando sobre os lemas recuperados a partir do reconhecimento de lexemas ordenados no processamento do sinal acústico ou correlato). Possíveis diferenças de procedimentos de implementação podem advir de questões relativas a incrementalidade, como será visto adiante. Observa-se, ainda, que o resultado da computação sintática, no caso da produção, é uma representação hierárquica a ser linearizada e morfofonologicamente codificada de modo que o enunciado em processamento possa ser efetivamente produzido em sons vocais (ou outro meio físico). No caso da compreensão, o resultado da computação sintática é uma estrutura hierárquica a ser semanticamente interpretada. Tem-se, assim, na produção, por um lado, e na compreensão, por outro, processos correspondentes à derivação bifurcada pós Spell-out que dá origem à interface fônica e semântica, respectivamente.

Para que relações de interface se tornem viáveis é, não obstante, necessário que os traços semânticos e semântico/formais do léxico se relacionem com outros sistemas cognitivos (conceituais e intencionais) e que seus traços fonológicos sejam definidos em função de propriedades de natureza articulatória e/ou acústica. Nesse sentido, pode-se tomar o léxico como o 
sistema em que se dá a interseção entre conhecimento lingüístico, conhecimento de ordem conceitual, enciclopédica, sistemas de crenças, dentre outros, e como sistema que possibilita o relacionamento entre a língua e o aparato físico responsável pela realização da fala. Em suma, ainda que parte do sistema cognitivo da língua, o que o léxico teria de especificamente lingǘstico estaria no fato de propriedades de ordem conceitual ou de ordem intencional (como as pertinentes à referência) serem vinculadas a traços formais, e de estas unidades semântico-formais terem uma representação fonológica a elas correspondentes, ou seja, serem lexicalizadas, viabilizando a materialização da língua em seu uso na fala. Note-se que é o fato de traços formais terem, em geral, motivação semântica (ou seja, advinda de representações em outros sistemas cognitivos) e de as propriedades dos mesmos se tornarem visíveis em padrões sistemáticos na interface fônica, o que garante que um conteúdo proposicional possa ser compartilhado entre falantes da língua, visto que a sistemacidade que pode ser detectada na interface fônica, uma vez respresentada no léxico em termos de traços formais é o que possibilita ao um sistema computacional universal atuar modularmente na derivação de expressões lingüísticas.

Percebe-se, pois, que a distinção entre o sistema computacional e o conhecimento adquirido estabelecida de forma clara no $\mathrm{PM}^{40}$ e a caracterização explícita de níveis de interface impondo restrições ao modo de operação do sistema computacional alteraram fundamentalmente o modo como o modelo de língua se inscreve no estudo da cognição humana. As restrições advindas de GU (estado inicial da língua interna) antes não motivadas em sistemas externos à língua ${ }^{41}$ passam a ser explicadas como necessárias, dadas as propriedades de todo um aparato cognitivo e físico requerido ao desempenho lingüístico, ou seja, em função da arquitetura do aparato processador humano. Os parâmetros de GU, ou seja, aquilo no que as línguas podem variar entre si, são também função das propriedades desse aparato. Além disso, o PM explicita a necessidade de uma medida de custo computacional, aparentemente concebido em termos de demandas à memória ativa (de trabalho) (Chomsky, 1999). Nesse sentido, a proposta

40. Observe-se que, em certo sentido, a proposta do PM recupera o que havia sito intuído por Humboldt, no século XIX (cf. Corrêa, 2006b).

41. A atribuição de restrições à forma das gramáticas das línguas humanas a GU - estado inicial da língua I, pode levar à crença de que as restrições atribuídas a GU teriam de estar especificamente codificadas nos genes humanos, o que não se mostra plausível. 
de derivação por fases $^{42}$ viria minimizar custo computacional. Além disso, o número de movimentos - operação com custo computacional - faria prever as demandas que uma dada computação imporia à memória de trabalho. Assim sendo, o modo como língua é apresentada no PM permite supor que o algoritmo de computação sintática, caracterizado nos termos de um sistema computacional universal operando em função da informação codificada nos elementos de uma numeração/arranjo lexican, pode ser tomado como algoritmo implementado no curso da formulação e da análise (parsing) de enunciados lingüísticos na produção e na compreensão em função das propriedades formais dos elementos do léxico (lemas) recuperados a partir de uma intenção de fala e da concepção de uma mensagem, por parte do falante, ou acessados a partir do reconhecimento de sua forma fônica (lexema) na compreensão. Em que medida essa possibilidade se mostra empiricamente adequada?

\section{Problemas de unificação}

Dois principais problemas se apresentam para a identificação entre algoritmo de computação sintática, tal como caracterizado em um modelo formal de língua e um algoritmo de implementação da computação conduzida em tempo real, na produção e na compreensão de enunciados lingüísticos - seja em termos funcionais, como em modelos psicolingüísticos, seja nos termos de modelos da atividade cerebral: (i) a direcionalidade da derivação (bottom-up) no modelo de língua, que implica a montagem de uma estrutura sintática da direita para a esquerda, ante a incrementalidade do processamento lingüístico no tempo, o que requer que a articulação e a análise do enunciado em processo de produção e de compreensão, respectivamente, seja conduzida da esquerda para direita (considerando-se a interface fônica pré-articulação, na produção, e a interface fônica que se apresenta à percepção, na compreensão); (ii) a aparente ausência de custo computacional das operações de movimento que resultam na ordenação canônica dos constituintes lingüísticos numa dada língua, ante o custo

42. O conceito de fase introduzido em Chomsky (1999) traz a hipótese de que uma derivação sintática procede passo a passo, a partir de sub-arranjos lexicais. O resultado da computação em cada fase é spelled-out, antes de os elementos de um novo sub-arranjo entrarem na derivação, dando origem a representações parciais PF e LF. 
mensurável da operação de movimento que altera essa ordem em função de demandas discursivas específicas. Cada um desses pontos será discutido a seguir.

\subsection{Direcionalidade e incrementalidade}

Uma característica do processamento humano que decorre do fato de este transcorrer no tempo é a incrementalidade. A análise do material lingüístico transcorre à medida que este é percebido, no caso da compreensão de enunciados, e a produção efetiva da fala não necessariamente pressupõe total planejamento conceptual do enunciado a ser produzido. Pausas após determinantes sugerem que algo a ser dito, com referência já definida, encontra-se em planejamento, mas que apenas a forma fônica do determinante do elemento mais à esquerda se encontra disponível para articulação (Butterworth, 1981). Além disso, o fato de tópicos ocuparem a periferia esquerda da sentença é indicativo de que o argumento sobre o qual um predicado será construído ou com o qual um evento será relacionado pode estar pronto para ser emitido antes que haja clareza acerca desse predicado ou do evento relacionado com o tópico na mente do falante.

Em estudo pioneiro sobre o tema, Kempen \& Hoencamp (1982) consideram que o modo de geração incremental impõe restrições ao design de possíveis mecanismos para a construção de estruturas sintáticas. Gramáticas top-down, em que toda a estrutura da sentença é explicitada antes da inserção de elementos do léxico, como nos modelos que serviram de base à Teoria da Complexidade Derivacional (cf. 2.1), não são vistas como compatíveis com essa característica. Kempen \& Hoencamp desenvolveram, então, uma gramática procedimental incremental - IPG (Incremental Procedural Grammar) - um algoritmo de geração/produção que parte de elementos do léxico, constrói, num primeiro estágio, estruturas em função de relações locais, e, num segundo estágio, ordena os constituintes de modo a serem produzidos (Kempen \& Hoencamp, 1982; 1987). Desde então, o modo de se expressar incrementalidade em modelos de processamento tem sido foco de interesse na pesquisa psicolingüística e o quão incremental a produção é, viria a ser posto em discussão. Ferreira (2000) argumenta, nesse sentido, ser necessário conceber a produção como parcialmente incremental, dado que, para que um DP em posição mais à esquerda seja produzido como sujeito é necessário que sua relação com o verbo tenha sido 
estabelecida antes de sua emissão. Isso não implica, contudo, que, no caso de verbos transitivos, o DP objeto tenha necessariamente de ter sido computado quando da emissão do sujeito e do verbo. Um CP ou um DP subspecificado pode ser suficiente quando o enunciado começa a ser produzido. Disfluências na fala, com pausas após o complementizador ou após o verbo podem ser tomadas como indicativas dessa subespecificação.

A necessidade de se levarem em conta os requisitos categoriais (e temáticos) de elementos do léxico para a definição das relações a serem computadas em modelos que visam a implementação efetiva de um algoritmo de gramática (via simulação computacional) favorece, assim, a proposta de derivações bottom-up. Por outro lado, a possibilidade de a sentença começar a ser emitida sem que elementos pós-verbais previsíveis tenham sido computados sugere que um modelo que parta da derivação do elemento mais profundamente encaixado à direita, como numa derivação minimalista, será empiricamente inadequado. Modelos de produção que fazem uso de gramáticas do tipo $\mathrm{TAG}^{43}$, ao recuperarem do léxico unidades correspondentes a estruturas sintagmáticas e/ou oracionais, descrevem uma estratégia top-down que consiste em definir o ambiente sintático no qual relações locais serão estabelecidas, o qual permite prever a presença de um constituinte sem que sua computação interna tenha sido efetivada. Procedimentos de natureza top-down compatibilizados com procedimentos bottom-up são, portanto, requeridos na caracterização da computação em tempo real.

Do ponto de vista do parser, processamento incremental diz respeito à construção de uma estrutura hierárquica, correspondente ao marcador frasal de sentenças, à medida que unidades do léxico são percebidas. Abney \& Johnson (1991) avaliaram diferentes algoritmos de parsing que analisam o input palavra por palavra, em função do quanto de memória sua implementação demandaria e do grau de ambigüidade local gerada ${ }^{44}$. Concluíram que um algoritmo top-down, que constrói nós não-terminais e posiciona os itens lexicais identificados em uma estrutura sintática pré-estabelecida, pode levar a um custo computacional desnecessário caso as estruturas previstas não sejam efetivamente utilizadas. Um algoritmo bottom-up, por ou-

\footnotetext{
43. Ver nota 6.

44. A construção do parsing, palavra por palavra, em sistemas de processamento automático não corresponde ao processamento humano que parte de unidades mais amplas percebidas em função de informação prosódica explícita ou implícita (na leitura).
} 
tro lado, ainda que elimine esse problema, faria prever maior demanda no processamento de orações encaixadas à direita do que à esquerda ou ao centro, o que contradiz evidências empíricas (Bever, 1970; Schlesinger, 1975; Hakuta, 1981; Gibson \& Thomas, 1999; Konieczny, 2000); Um parser direcionado de forma ascendente teria de aguardar a identificação de uma oração encaixada à direita (em função da presença de um elemento de classe fechada do tipo complementizador), mantendo toda uma seqüência de elementos do léxico anterior a este não analisada na memória de trabalho, de modo que a análise da sentença tivesse início a partir do nível mais baixo de encaixamento. Em (1), por exemplo, o parser teria de manter uma seqüência de itens do léxico não analisada na memória até que a análise sintática partisse do PP da oração mais à direita, o que é contrariado pelo efeito de labirinto (garden-path) constatado no processamento imediato da oração relativa como completiva. Efeitos desse tipo podem ser tomados como ilustrativos de que a oração principal é imediatamente processada, da esquerda para a direita, e de que o parser tem como prioridade identificar os argumentos do verbo desta oração, estabelecendo, assim, relações estruturais correspondentes à relação proposicional que deu origem à sentença (uma vez que esta foi produzida por um falante). De forma análoga, o fechamento de uma oração principal antes do reconhecimento de uma oração relativa à direita pode impedir a análise sintática da mesma (Corrêa, 1995). Assim sendo, ao mesmo tempo em que um algoritmo bottom-up não se mostra adequado para dar conta do processamento de orações encaixadas à direita, é necessário que as propriedades dos itens lexicais em questão, pertinentes a transitividade (ou mesmo à grade temática de predicadores), sejam levadas em conta na construção do marcador-frasal da sentença.

(1) Maria contou ao amigo que vai para a Bahia que gosta de acarajé.

Considerando-se que uma derivação minimalista é direcionada de forma ascendente e que as unidades (fases), seriam delimitadas assim que relação de natureza proposicional fosse computada ${ }^{45}$, teríamos, no exemplo em (1) uma fase definida a partir da relação (pro gosta de acarajé), cujo DP sujeito (pro) só poderia ser semanticamente interpretado após a análise de Maria como sujeito da oração principal. Efeitos de reativação de antece-

45. Ver nota 43. 
dentes à altura do gap (constituinte vazio) em orações encaixadas, por sua vez, evidenciam que a sentença mais à esquerda é imediatamente analisada (Nicol \& Swinney, 1989). Assim sendo, uma derivação minimalista, tal como se apresenta na teoria lingüística, não se mostra adequada para caracterizar computação on-line.

O problema da direcionalidade da derivação no parsing de sentenças é particularmente abordado por Phillips (1996), ao propor um modelo unificado que denomina PIG (parser is grammar) (Phillips, 1996). O autor baseia-se em testes para identificação de constituintes (constituency tests), tradicionalmente usados no estudo da sintaxe, e observa que os resultados contraditórios a que muitos desses testes levam seriam explicáveis pela incrementalidade do processamento (id. ibi.; Phillips, 2003b). Argumenta, então, a favor de uma derivação da esquerda para a direita por meio da qual elementos do léxico são concatenados dois a dois à medida que são identificados.

Em suma, um algoritmo de derivação de expressões lingüísticas que opere da direita para esquerda de modo a construir estruturas sintáticas de forma ascendente não pode ser tomado como modelo da computação sintática conduzida por um parser ou por um formulador sintático. Em ambos os casos, é necessário que se conceba um algoritmo que atue sobre a informação proveniente dos traços formais de elementos do léxico - sejam estes os lemas recuperados no acesso lexical que antecede a formulação sintática, ou os lemas recuperados via o reconhecimento de lexemas a partir da segmentação do continuum da fala, na compreensão - tanto de forma top-down, na definição de domínios sintáticos, quanto de forma bottom-up, para que a concatenação dos elementos do léxico se dê em função de seus requisitos categoriais/temáticos. Na seção 3.1., apresenta-se a concepção de um modelo misto de computação on-line no qual são exploradas a distinção entre elementos de categorias funcionais e lexicais, na interação entre o léxico e domínios conceptuais e intencionais, e a hipótese de bare phrase (Chomsky, 1995b).

\subsection{Dois tipos de movimento sintático}

Outra dificuldade que se apresenta para que se tome uma derivação minimalista como modelo da computação on-line reside na natureza distinta dos processos representados por meio da operação de movimento. Movimento descreve dois tipos de processos. O primeiro diz respeito à 
ordenação de elementos do léxico de acordo com um dado padrão correspondente à ordem canônica dos constituintes sintáticos na língua. Realizase, basicamente, em função da presença necessária de núcleos funcionais com traço EPP na numeração/arranjo lexical. Esse tipo de movimento (movimento de argumento e de núcleo) ${ }^{46}$ para determinadas posições é, portanto, compulsório. O segundo tipo de movimento diz respeito à alteração dessa ordenação canônica, em função da presença eventual de determinados traços formais (como por exemplo, + Q) em elementos de uma dada numeração/arranjo lexical.

Um modelo formal de língua, concebida em estado virtual, não precisa explicar o porquê de uma dada numeração/arranjo lexical ser constituída/o de determinados elementos. Assim sendo, a presença necessária ou eventual de traços formais que deflagram movimento é irrelevante do ponto de vista do sistema computacional. Além disso, dado o critério de adequação explanatória, faz-se necessário explicitar de que modo diferentes ordenações podem advir de um estado inicial comum. Em um modelo de computação on-line, por outro lado, a constituição do equivalente a uma numeração/arranjo lexical - seja na produção ou na compreensão - é função do estado do léxico do falante/ouvinte (se o valor dos parâmetros do léxico encontram-se ou não fixados), de sua intenção de fala e da mensagem a ser produzida, num particular contexto de enunciação. Assim sendo, o fato de a recuperação de elementos do léxico que define o que estará disponível para a computação (ou seja, o equivalente a numeração/arranjo lexical em um modelo de processamento) não ser feita de forma aleatória, quando se considera a língua em uso, requer que se diferenciem qualitativamente as operações de movimento implementadas em função da natureza dos traços que as deflagram. Traços cuja presença é compulsória correspondem a movimento sem custo computacional mensurável no tempo, enquanto que aqueles cuja presença é função de demandas discursivas específicas acarretam custo computacional mensurável.

Parâmetros de ordem parecem ser fixados em momento bem precoce da aquisição da língua, em função do acento da frase fonológica (Christo-

46. Estamos vinculando os movimentos responsáveis pela ordenação canônica à presença do traço EPP para facilitar a exposição. Esse traço determina, contudo, apenas movimento de DP sujeito (em línguas SV) ou objeto (em línguas OV). Movimento de núcleo não é fácil de ser explicado no âmbito da sintaxe restrita (ver Nota 34). 
phe et al. 2003; Gout \& Chistophe, 2006). A vinculação entre ordem e papéis temáticos pode, não obstante, não ser imediata. Esta pode vir a ser estabelecida via identificação de padrões e dependência a estratégias, privilegiando-se a posição inicial para o agente, dado que não há uma vinculação totalmente determinística entre estes (Bever, 1970; Townsend \& Bever, 2001). Assim sendo, é possível que o "caminho neurológico" para a ordenação de constituintes fique rigidamente definido uma vez que parâmetros pertinentes a ordem sejam fixados e que a atribuição de papéis temáticos seja um problema a ser solucionado em momento subseqüente do processamento, já na esfera do processamento semântico. A dissociação entre posição sintática e papel temático poderia explicar a dificuldade de crianças de 3 anos $^{47}$ e de portadores do DEL (Friedmann \& Novogrodsky, 2004; a sair) na vinculação entre ordem e papéis temáticos em tarefas de compreensão, ainda que a produção não evidencie problemas pertinentes à expressão de relações temáticas na ordenação. Assim sendo, é necessário que um modelo de computação on-line busque uma solução formal para o posicionamento imediato de constituintes em sua localização canônica.

A necessidade de um elemento se mover da posição em que é (ou na qual seria) inicialmente posicionado - movimento de QU, por exemplo, também é definida em função da fixação de parâmetros, nesse caso, pertinentes a movimento. Movimento QU, no caso de interrogativas e relativas, topicalização, clivagem, focalização, é uma operação cuja implementação decorre da maneira como uma dada língua codifica seu particular modo de atender a demandas discursivas pertinentes à força ilocucionária, referência, definição de tópico e expressão de foco. Diferentemente do movimento de núcleo ou de DPs sujeito / objeto, esse segundo tipo de movimento não é compulsório na geração da expressão lingüística. Ocorre em função da presença de um traço ( $+Q$, por exemplo), que informe o sistema computacional da necessidade de deslocamento de constituintes nos elementos em uma dada numeração/arranjo lexical. No caso da produção da fala, a presença/valor de tal traço seria decorrente de demandas discursivas específicas como formular uma pergunta, colocar um elemento em evidência, estabelecer foco distintivo, alterar o tópico. Tais

47. Dados obtidos no LAPAL (Laboratório de Psicolingüística e Aquisiçào da Linguagem) para o grupo de controle de um teste de avaliação de habilidades lingüísticas com vistas para contribuir para o diagnóstico do DEL (Déficit Específico da Linguagem), Corrêa (em prep). 
operações têm custo computacional mensurável no tempo, no processamento lingüístico, e são particularmente afetadas no caso de afasias adquiridas e do DEL (cf. Leonard, 1998; Silveira, 2002; Jakubowicz, 2006; Correa \& Augusto, submetido; Lima, Corrêa \& Augusto, submetido).

Dadas essas distinções, não é possível assumir uma derivação minimalista como modelo adequado da computação conduzida no tempo. Um modelo da computação on-line deve prever custo computacional diferenciado para movimento que, numa derivação lingüística, posiciona elementos de acordo com uma ordenação canônica, e movimento que altera essa ordem neutra (que pode ser obtida em resposta a perguntas como $O$ que aconteceu?).

\section{Por um modelo da computação on-line}

Modelos psicolingüísticos da produção de enunciados mostram-se pouco explícitos no que concerne às operações conduzidas em função da informação codificada nos lemas durante a formulação gramatical. Modelos de parsing, por sua vez, ainda que mais explícitos do que aqueles, não deixam claro de que modo o conhecimento da língua rege as ações do parser. Modelos psicolingüísticos carecem, pois, de uma teoria de língua suficientemente informativa para que as ações de um formulador sintático e as de um parser possam ser satisfatoriamente caracterizadas. Uma derivação minimalista, ainda que se aproxime de uma concepção de computação online, não pode ser imediatamente identificada com esta. De qualquer forma, o fato de uma derivação minimalista ser regida pelo PIP e a compatibilidade que se observa entre sua concepção e modelos de produção e de compreensão encorajam a adaptação do que se apresenta como computação na língua em estado virtual para computação em tempo real. A seguir, apresentam-se considerações preliminares relativas ao modo como um modelo de computação on-line poderia ser concebido assumindo uma concepção minimalista de língua.

\subsection{Interseç̧ões no léxico e a direcionalidade da computação on-line}

Para viabilizar a existência de níveis representacionais de interface como resultado de uma derivação lingüística, é necessário supor interação entre 
o léxico e os demais sistemas cognitivos que atuam no desempenho lingüístico. Caracterizar de que modo essa interação se estabelece não é objeto da teoria lingüística. Tal interação é, no entanto, fundamental quando se considera o modo como a computação lingüística é efetivamente implementada na produção e na compreensão de enunciados lingüísticos. Argumenta-se aqui que, ao se considerar o modo como traços formais do léxico se relacionam com sistemas conceptuais e intencionais, é possível propor um modelo misto que satisfaça à necessidade de compatibilizarem-se procedimentos de natureza top-down e bottom-up para dar conta da incrementalidade do processamento lingüístico.

A teoria lingüística refere-se a sistemas conceptual e intencional de forma indiferenciada. No âmbito da Psicologia cognitiva, contudo, uma vasta literatura dedica-se à caracterização da natureza de conceitos, de sua relação com um léxico, além das diferentes estruturas cognitivas necessárias para que relações de ordem conceptual se estabeleçam (Laurence \& Margolis, 1999). Memória semântica, conhecimento enciclopédico, memória episódica, além de estruturas conceptuais complexas como os esquemas são alguns dos construtos concebidos nesse campo, os quais podem ser úteis na caracterização do modo como o significado lexical incorpora traços vinculados a essas representações. $\mathrm{O}$ conceito intencionalidade, por sua vez, faz parte do vocabulário da Filosofia e apresenta um tópico que se situa na interface entre Filosofia da Linguagem e Filosofia da Mente ${ }^{48}$. Este diz respeito a estados mentais, como o de perceber, lembrar, desejar, ansiar, saber, pretender, sentir, dentre outros.

48. Embora originário da filosofia escolástica, o conceito de intencionalidade foi trazido à discussão contemporânea, em fins do século XIX, por Franz Brentano, que definiu fenômenos mentais como intencionais, por incluir um objeto ao qual são dirigidos (percebe-se, deseja-se, ama-se, afirma-se, etc. algo). Segundo Jacob (2003), Chomsky concebe referência como uma ação intencional (não como uma relação entre palavras e objetos). Tendo em vista a correspondência assumida entre mente e cérebro, sistema intencional pode ser entendido como o aparato mental / cerebral responsável por tais estados mentais. A indissociação entre sistema conceptual e intencional no Minimalismo parece ser indicativa do quão obscuros são esses sistemas particularmente, o que se entende por sistema intencional, no estudo da cognição humana. Nesse sentido, a seguinte citação é ilustrativa: "Os sistemas que acessam representações de significado podem ser chamados de sistemas "conceptuaisintencionais", onde "intencional" é o termo filosófico tradicional para essa relação misteriosa de "sobre algo" [aboutness]: coisas dizem respeito a alguma coisa. Assim, os sistemas conceptuais-intencionais, que são em grande parte misteriosos, são sistemas que acessam certos aspectos de expressões que permitem que se faça o que se faz com a língua: expressar pensamentos, falar sobre o mundo, o que quer que seja". (Chomsky, 2000b, p.8-9.). 
Está fora do escopo do presente artigo explorar o modo como estruturas conceptuais e intencionais se relacionam com o léxico mental. Propõese, não obstante, que a distinção entre categorias funcionais e lexicais é uma expressão do modo como o léxico interage com esses sistemas. Categorias lexicais estariam diretamente relacionadas a sistemas de natureza conceptual, dado que seus elementos podem ser decompostos em uma série de traços semânticos e seus traços categoriais dizem respeito basicamente a distinções de ordem conceptual, que permitem a categorização de entidades e eventos. Categorias funcionais, por outro lado, são pobres em traços semânticos, e estes vinculam-se mais diretamente a sistemas de natureza intencional, visto que codificam aspectos pertinentes à referência e à força ilocucionária atribuída ao enunciado lingüístico. Essa distinção permite diferenciar a direcionalidade da computação conduzida a partir do acesso a elementos de categorias funcionais e categorias lexicais. $\mathrm{O}$ acesso a traços semânticos/formais de categorias funcionais daria origem a derivações do tipo descendente (top-down), enquanto o acesso a traços semânticos/formais de elementos de categorias lexicais daria origem a derivações do tipo descendente (bottom-up), gerando estruturas a serem acopladas nas posições subspecificadas de complementos de núcleos funcionais (em sua projeção mínima) (ver Fig. 1 e 2).

Feita essa distinção, um modelo de produção, em que se caracteriza a computação on-line na perspectiva do PM, partiria de um estado mental do falante, ou seja, de uma intenção de fala, na qual interferem o contexto, seu modelo do interlocutor, e todos os aspectos pertinentes a um ato de fala, dando origem à recuperação de traços semânticos ${ }^{49} /$ formais de elementos de categorias funcionais ${ }^{50}$ do léxico. Os traços relativos à força ilocucionária pretendida seriam codificados em C (em sua projeção máxi$\mathrm{ma}$ ), propriedades pertinentes à referência a um evento concebido no tempo seriam codificados em $\mathrm{T}$, em sua projeção máxima, gerada como complemento de $\mathrm{C}^{51}$, e traços pertinentes às entidades minimamente en-

49. Considera-se aqui que traços semânticos podem codificar não apenas informação de natureza conceptual, como de natureza pragmática.

50. Considera-se que o acesso lexical possa ser feito composicionalmente, a partir de traços semânticos e semântico-formais. Somente em momento posterior à computação, os lexemas (conjunto de traços fonológicos) correspondentes seriam recuperados.

51. A codificação de outros aspectos pertinentes à referência como Aspecto e Modo também pode ser prevista. 
volvidas em um dado evento seriam codificados em D (em sua projeção máxima), em um espaço derivacional paralelo (baseado na idéia de "derivational cascades” em Uriagereka, 1999), visto que a função sintática da estrutura derivada a partir de D só seria definida em função das propriedades do verbo (ver Fig.1).

O modelo de produção também inclui a concepção de uma da mensagem (uma proposição total ou parcialmente concebida, a partir de um tópico, explicitamente delimitado ou não) (cf. Garrett, 2000 Levelt, 1989; 1995). O conteúdo proposicional ou tópico dessa representação inicial possibilitaria o acesso a elementos de categorias lexicais, no que concerne a seus traços semânticos e semântico/formais. O acesso a estes (traços categoriais e grade temática ${ }^{52}$ ) daria origem à derivação bottom-up de NPs, VPs ou PPs, a serem acoplados como complementos de $\mathrm{D}$ e de $\mathrm{T}$ nas árvores geradas de forma descendente a partir de elementos funcionais. ${ }^{53} \mathrm{Uma}$ vez que parâmetros relativos a ordem estariam fixados, considera-se que 0 DP gerado em espaço derivacional paralelo possa ser imediatamente acoplado na posição estrutural correspondente à sua posição linear - tópico ou suejeito. ${ }^{54}$ Assumindo-se um DP como uma fase na computação sintáti$\mathrm{ca},{ }^{55}$ uma vez que um DP fosse acoplado na posição de sujeito (Spec TP) na árvore gerada a partir de $\mathrm{C}$ em uma língua SVO, este poderia ser efetivamente produzido, da esquerda para a direita, antes de um vP ou um DP complemento serem computados. Desse modo, é possível caracterizar o caráter incremental da produção e prever disfluências que revelem dúvidas

52. Para que se mantenha que o sistema computacional tem acesso exclusivo a traços formais é necessário considerar que informação temática pode ser temporariamente representada como formal, uma vez que elementos do léxico entrem numa numeração, ou seja, sejam recuperados do léxico para a formulação do enunciado.

53. A formalização dessa proposta encontra-se em andamento e versões preliminares foram apresentadas em Corrêa \& Augusto, 2005; 2006; a sair. Note-se que seria necessário propor a derivação de estruturas transitivas em que VP aparece como complemento de vP. Esse ponto vem sendo explorado nos trabalhos referidos.

54. Ver Corrêa e Augusto a sair para que este posicionamento imediato possa ser compatibilizado com a satisfação de requisitos temáticos.

55. Chomsky apresenta fases como proposições completas, que têm como correspondentes sintáticos fases lexicais forte (VP e vP) seguidas de fases funcionais fortes (TP e CP). Consideramos, contudo, que para que o que o conceito de fase seja incorporado em um modelo de computação online, DPs tópicos e DPs sujeitos (em língua SVO, pelo menos) devem corresponder a fases. Nesse sentido, incorporamos o conceito de fase em Carnie \& Barss, 2006, que inclui um argumento isolado como fase. 
do falante quanto à seleção lexical de um verbo e ou de seu complemento ao longo da produção do enunciado ainda que o sujeito já tenha sido produzido. Torna-se possível também incorporar ao modelo de produção um monitorador que atue no limite das fases, o qual teria acesso à informação correspondente à PF e LF parciais do DP mais à esqueda já morfononnologicamente codificado ou produzido. Fases, em um modelo de computação online, seriam assim unidades encapsuladas de processamento sintático que, uma vez codificadas morfofonologicamente (não necessariamente emitidas), tornam-se acessíveis a um monitorador, que verifica a relação entre o plano da intenção/mensagem e o que foi efetivamente gerado ou produzido ${ }^{56}$.

No que diz respeito ao parser, entende-se que a atividade de análise sintática pressupõe a percepção do sinal acústico da fala em contornos prosódicos, os quais atuam de forma implícita na leitura (Fodor, 1998; Lourenço-Gomes, Maia \& Moraes, 2005). Assim sendo, assume-se que o parser parte do pressuposto de uma força ilocucionária relativa a um tópico ou a uma proposição (que pode ser expressa na entonação). Uma árvore topdown derivada a partir de $\mathrm{C}$ em sua projeção máxima pode ser, portanto, concebida, a qual inclui TopP e/ou desdobra-se até T, em função da percepção imediata de uma unidade com determinado contorno prosódico. A identificação de um elemento de D possibilita a criação de um DP, no qual a presença de $\mathrm{N}$ assim como de modificadores deste pode ser antecipada, de modo que o reconhecimento de $\mathrm{N}$ ou de Adj. na ordem linear dos elementos do léxico possibilite a definição da estrutura do $\mathrm{DP}^{57}$. Este é representado imediatamente como Top, se com contorno entonacional marcado, ou permanece na memória de trabalho sem que sua posição na árvore gerada a partir de $\mathrm{C}$ seja definida até o reconhecimento do verbo que, uma vez acoplado à árvore gerada de forma descendente até $\mathrm{T}$, como complemento deste, possibilita o acoplamento do DP inicial em posição de sujeito $^{58}$ e a busca pelos demais elementos que satisfaçam sua estrutura argumental na seqüência linear em que os constituintes se apresentam.

56. Para um modelo de produção que explora essa possibilidade aliada à ação de um sistema monitorador ver Corrêa e Rodrigues (2005); Rodrigues (2006).

57. Nestas considerações iniciais, questões pertinentes à estrutura do DP, com a possibilidade de projeções do tipo NumP (cf. Augusto, Ferrari-Neto \& Correa, 2006) não são levadas em conta, mas a necessidade de estas serem incluídas pode ser considerada a partir do reconhecimento de informação de ordem morfológica.

58. Questões relativas à operacionalização de uma derivação que inclui $v$ não são aqui levadas em conta. Ver Corrêa \& Augusto (2006) para o encaminhamento de uma solução formal para as mesmas. 
As Fig. 1 e 2 ilustram esquematicamente o acesso ao léxico (com interação com sistemas intecionais/conceituais), o direcionamento descendente a partir de categorias funcionais, ascendente, a partir de categorias lexicais e o posicionamento imediato na produção e na compreensão da sentença afirmativa, com verbo de um argumento, "O menino pulou". Para simplificação, não foram levadas em conta categorias funcionais tais como Num, Gen no DP, Asp, nem se considerou o modo de representar v, neste esquema. ${ }^{59}$

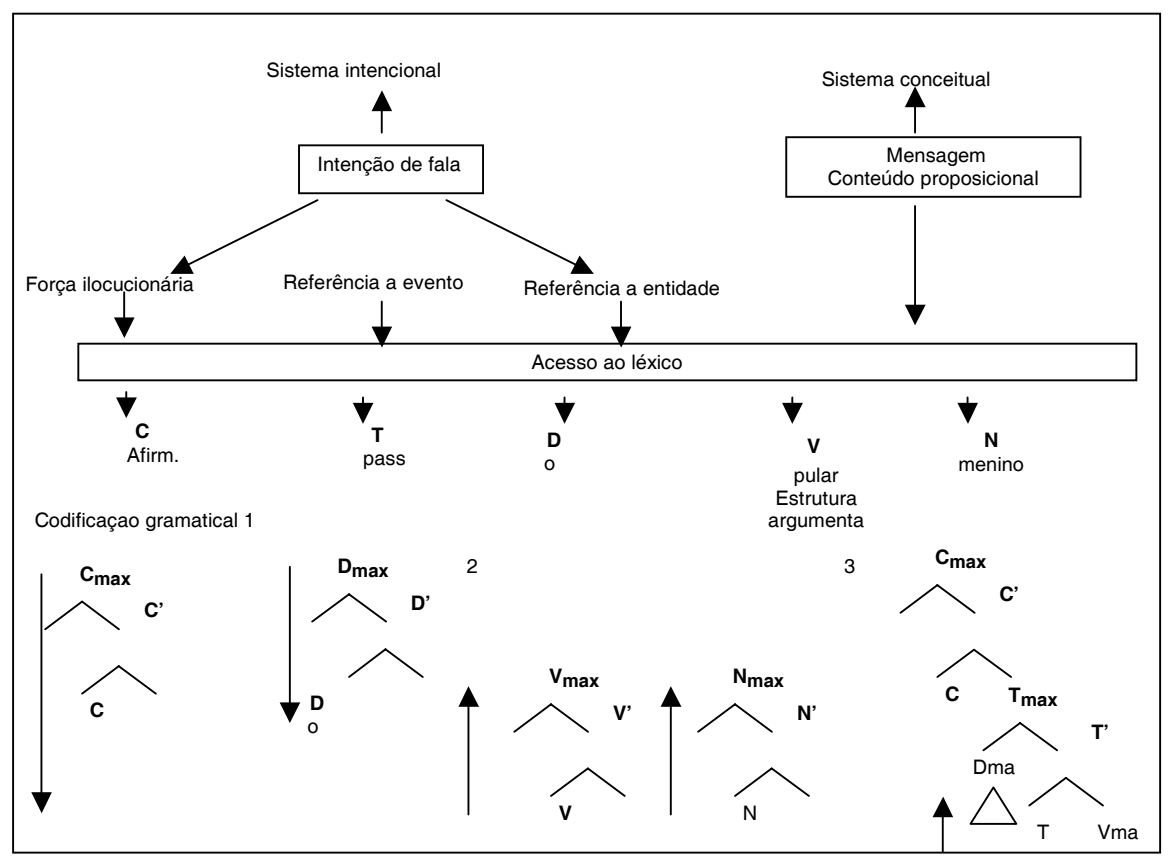

Figura 1: Acesso ao léxico e computação sintática na produção. 


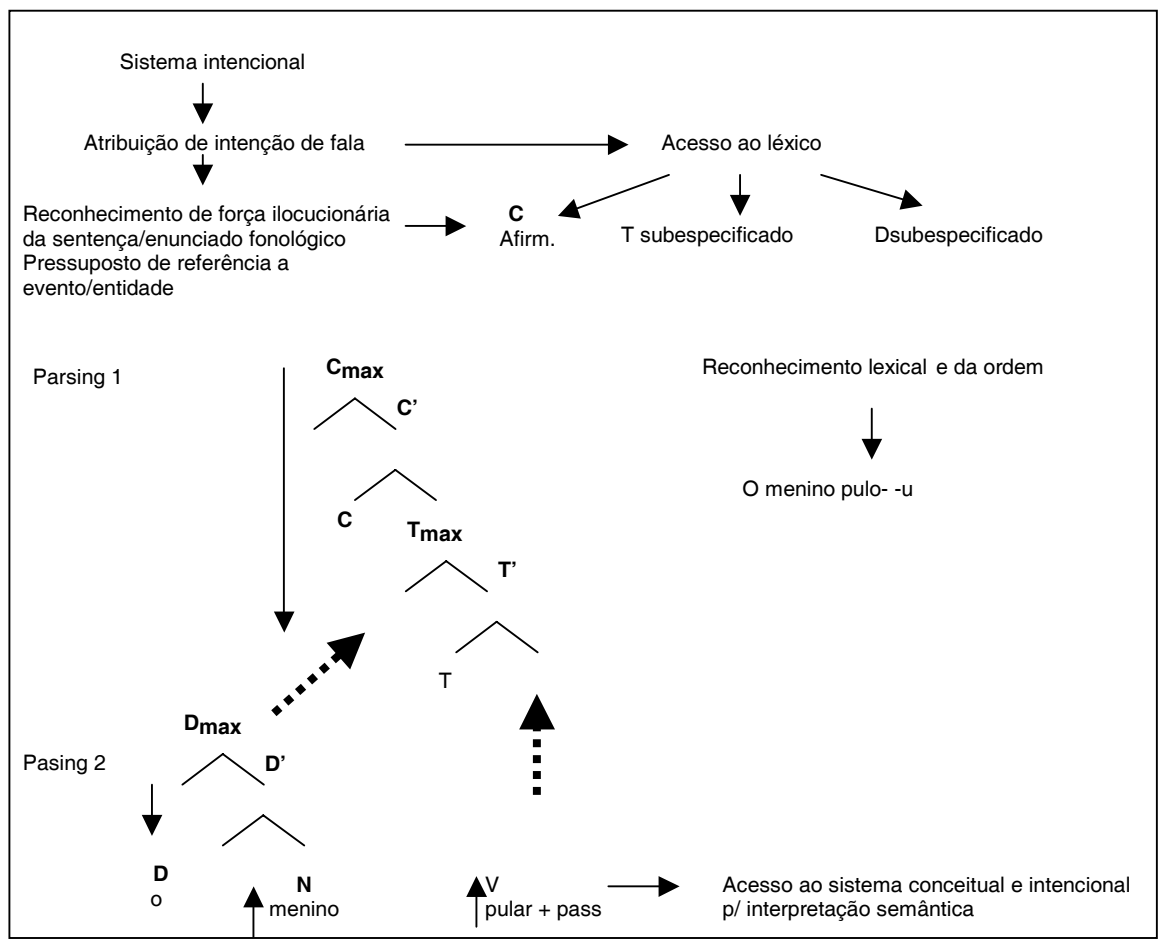

Figura 2: Acesso ao léxico e computação sintática na compreensão.

\subsection{Movimentos com e sem custo computacional}

Em 2.2, a natureza distinta de processos caracterizados formalmente em termos de uma operação de movimento em um modelo de língua em estado virtual foi considerada. Um modelo da computação on-line tem, pois, de explicitar formalmente essa distinção, dado que a mesma acarreta custo computacional diferenciado quando se considera a língua em uso. Assim sendo, movimento de verbo, movimento de sujeito/objeto, assim como movimento interno ao $\mathrm{DP}^{60}$, não seriam implementados no curso de cada derivação lingüística. Esse tipo de informação no léxico (como

60. O posicionamento de possessivos e adjetivos no DP também seria decorrente da presença necessária de um traço indicativo dessa informação em $\mathrm{D}$. 
propriedades associadas ao traço EPP) garantiria a implementação do posicionamento automático de núcleos e DPs em sua posição canônica, como mencionado acima (2.3), o que eliminaria qualquer custo computacional. A presença ocasional de traços do tipo $+\mathrm{Q}$, +Foco, em elementos recuperados do léxico, em função de demandas discursivas específicas, acarretaria, em princípio, maior custo.

Do ponto de vista do ouvinte, o reconhecimento de um elemento movido na periferia esquerda implica sua manutenção em estado ativo na memória até que este seja reativado em sua posição canônica (Holmes \& O'Regan, 1981; Nicol \& Swinney, 1989; Stowe, 1986, King \& Just, 1991; Muller, King \& Kutas, 1995; Kluender \& Kutas, 1993). Do ponto de vista do falante, movimento para a periferia esquerda é decorrente de uma determinada intenção de fala (força ilocucionária interrogativa, estabelecimento de tópico, focalização etc.). Isso implica a manutenção de um elemento ativo na memória até que o verbo seja computado e morfofonologicamente codificado, quando a posição daquele na ordenação canônica se veria expressa ${ }^{61}$. A necessidade de um procedimento discursivamente marcado - que acarreta manutenção de um dado elemento particularmente ativo na memória de trabalho, explicaria o maior custo computacional associado a movimento QU, sendo este custo variável em função de fatores contingenciais como tamanho e tipo de DP, animacidade dentre outros (cf. Traxler, Morris \& Seely, 2001; Mak, Vonk \& Schriefers, 2002, Gordon, Hendrick \& Johnson, 2001; Warren \& Gibson, 2002).

Uma dificuldade para a formalização do posicionamento imediato de DPs em sua posição canônica diz respeito à satisfação de requisitos temáticos. No que concerne à produção, estes são estabelecidos em função da formulação da mensagem por parte do falante e codificados em função de uma relação não totalmente determinística entre posição sintática/linear e a grade temática do verbo. A definição dos mesmos, em termos conceptuais, e o conhecimento dessa relação precisam ser representados de modo que o sistema computacional possa acoplar um determinado DP a uma

61. Dados experimentais são escassos quanto a esse ponto, restringindo-se basicamente à produção de pacientes afásicos, que evidenciam dificuldade na produção de sentenças que evolvem movimento de constituintes para a periferia esquerda (cf. Basiaanse \& van Zonneveld (1998); Friedmann (2000)). 
posição de complemento de $\mathrm{V}$ ou de $\mathrm{P}$, ou à posição de sujeito. Não é claro como essa informação pode ser formalizada de modo a tornar-se acessível ao sistema computacional nos termos de uma derivação minimalista. Uma solução imediata (ainda que não satisfatória) seria tomar papéis temáticos como traços formais. ${ }^{62}$

Do ponto de vista do parser, na compreensão de enunciados lingüísti$\cos$, a ordenação de constituintes constitui informação de interface pertinente a funções sintáticas/caso. A identificação dos papéis temáticos dos constituintes ordenados é função do acesso aos traços semânticos dos predicadores. Uma vinculação entre posição linear/sintática e papel temático (determinística apenas no caso da relação complemento-tema, ainda que tema não seja necessariamente complemento) parece ser pressuposta pelo parser, mas, uma vez que essa relação não é totalmente determinística, é possível que tenha de ser estabelecida em função de freqüência de uso (motivada por fatores de ordem cognitiva, não diretamente lingüística, pertinentes à produção), tornando a posição de sujeito privilegiada para o papel de agente (cf. Townsend \& Bever, 2001 e referências ali contidas). Uma vez que o reconhecimento de papéis temáticos não seria exclusivamente dependente de ações no âmbito de um módulo lingüístico, a dificuldade de crianças na aquisição de conhecimento pertinente a essa vinculação na compreensão e não na produção seria explicada e a dificuldade de portadores de DEL poderia ser atribuída ao custo adicional que tal processamento acarretaria. Um modelo da computação on-line precisa, pois, garantir uma vinculação entre posição sintática e papel temático, dando margem para que tal interpretação seja definida em função de relações de interface.

As hipóteses acerca de um modelo de computação on-line que seja acoplado a modelos de produção e de compreensão aqui encaminhadas precisam ser caracterizadas de forma a serem implementadas, testadas à luz de dados comportamentais ou provenientes de respostas cerebrais. No momento, o argumento defendido é o de que conceber processamento online fora do contexto de modelos de produção/compreensão pode não ser produtivo. Apenas nesse contexto a interação entre léxico e sistemas conceptuais pode ser pensada, o que parecer ter conseqüências para o modo de condução da computação. Além disso, é nesse contexto que demandas discursivas podem ser caracterizadas, e avaliado o custo relativo do processa-

62. Ver nota 29. 
mento de sentenças com movimentos com custo computacional dentro e fora do discurso.

\section{Para concluir}

Os objetivos deste artigo foram recuperar um pouco da história da relação entre Lingüística e Psicolingüística, chamando atenção para a convergência que se observa entre desenvolvimentos da lingüística gerativista e da psicolingüística, avaliar a possibilidade de uma derivação minimalista ser tomada como representação da computação efetivamente conduzida em tempo real, e apresentar considerações iniciais acerca de um modelo de computação on-line formulado à luz da proposta minimalista, no contexto do que chamamos de uma teoria integrada da competência lingüística. Dois problemas foram aqui destacados: (i) a questão da direcionalidade da derivação lingüística ante o caráter incremental da computação conduzida ao longo do tempo e (ii) a necessidade de se prever custo computacional diferenciado para operações de movimento que, numa concepção de língua em estado virtual, dizem respeito à fixação de parâmetros de ordem no curso da aquisição da linguagem, e operações de movimento que respondem a demandas discursivas.

Argumentou-se que o tratamento da computação on-line requer que se considere o modo como elementos do léxico interagem com sistemas conceituais/intencionais para que o acesso lexical seja conduzido em função de uma intenção de fala e da concepção de uma mensagem. Uma interação diferenciada entre elementos de categorias lexicais e funcionais com sistemas conceptuais e intencionais definiria a direcionalidade top-down e bottom-up da computação on-line. O posicionamento imediato do DP sujeito/objeto na posição estrutural correspondente à sua posição canônica (em função da fixação de parâmetros pertinentes à ordem) explicaria a ausência de custo computacional desse tipo de movimento sintático. O modo como este posicionamento imediato pode ser conciliado com a satisfação de requisitos temáticos é um problema para o qual uma solução formal vem sendo buscada (Corrêa \& Augusto, 2006; a sair) e previsões relativas ao custo computacional diferenciado de operações de movimento de núcleo/argumento e de operações que atendem a demandas discursivas vêm sendo confrontadas com dados da literatura relativa ao déficit específico da linguagem (Corrêa \& Augusto, submetido) e ao agramatismo (Lima, Cor- 
rêa e Augusto, submetido), em diferentes línguas. Uma série de problemas tem, não obstante, de ser resolvida para que o modo como conhecimento lingüístico é posto em uso, seja formalmente caracterizado. Considera-se que uma teoria integrada da competência lingüística, na qual a computação lingüística é concebida no contexto de modelos de processamento lingüístico, é necessária para a caracterização desse processo, e o contexto minimalista mostra-se promissor para o desenvolvimento de uma teoria dessa natureza.

Recebido em maio de 2007 Aprovado em março de 2008 E-mail: lscorrea@let.puc-rio.br

\section{REFERÊNCIAS BibLIOGRÁFicas}

Abney, Steven \& Mark Johnson. 1991. Memory Requirements and Local Ambiguities of Parsing Strategies. Journal of Psycholinguistic Research 20/3: 233-250.

Adger, David. 2003. Core Syntax A Minimalist Approach. Oxford/New York: Oxford University Press.

Augusto, Marina R. A. 2005. As relações com as interfaces no quadro minimalista gerativista: uma promissora aproximação com a Psicolingüística. In: Neusa Salim Miranda \& Maria Cristina Lobo Name (Orgs.) Lingüística e Cognição. Juiz de Fora: Editora da UFJF.

Augusto, Marina Rosa Ana, Jose Ferrari Neto \& Letícia Maria Sicuro CORRÊA. 2006. Explorando o DP: a presença da categoria NumP. Revista de Estudos da Linguagem da UFMG 14/2: 245-275.

BastiaAnse, Roelien \& Ron Van Zonneveld. 1998. On the relation between verb inflection and verb position in Dutch agrammatic aphasia. Brain and Language 64: 165-181.

Bever, Thomas G. 1970. The cognitive basis for linguistic structures. In: Hayes John R. (Ed.) Cognition and the Development of Language. New York: John Wiley \& Sons.

Bobaljik, Jonathan David. 2001. In terms of Merge: Copy and Head Movement. In: Pensalfini, Robert \& Hiroyuki Ura (Orgs.) Papers on Minimalist Syntax. MIT Working Papers in Linguistics 27: 41-54. 
Bock, Kathryn \& Willem J.M. Levelt. 1994. Language production: grammatical encoding. In: Morton Ann Gernsbacher (Ed.) Handbook of Psycholinguistics. San Diego/ CA: Academic Press.

Bogdan, Radu. 1993. L'Histoire de la Science Cognitive. In : Lucien Sfez (Org.) Dictionnaire Critique de la Communication. Paris: PUF.

Borer, Hagit. 1984. Parameytric Syntax. Dordrecht: Foris.

BresnAn, Joan. 1978. A realistic transformational grammar in Linguistic Theory and Psychological Reality. In: Morris Halle, Joan Bresnan \& George A. Miller (Orgs.) Linguistic Theory and Psychological Reality. Cambridge/ MA: MIT Press.

. 1982. The Mental Representation of Grammatical Relations. Cambridge/ Mass: MIT Press.

. 2001. Lexical-Functional Grammar. Oxford: Blackwell.

Butterworth, Brian. 1981. Speech errors: old data in search of new theories. Linguistics 19, 7/8: 627-662.

Caramazza, Alfonzo, Alessandro Laudana \& Cristina Romani. 1988. Lexical access and inflectional morphology. Cognition 28:297-332.

Carnie, Andrew \& Andrew Barss. 2006. Phases and Nominal Interpretation. Research in Language. (Download Prepublication version).

ChesI, Cristiano. 2004. Phases and Cartography in Linguistic Computation: toward a Cognitively Motivated Computational Model of Linguistic Competence. $\mathrm{PhD}$ Thesis, Università di Siena.

Chомsкy, Noam. 1957. Syntactic Structures. Mouton: Den Haag. .1965. Aspects of the Theory of Syntax. Cambridge: MIT Press. 1981. Lectures on Government and Binding. Dordrecht: Foris. .1986. Knowledge of Language, its nature, origin and use. New York: Praeger.

1994. On Linguistics and Politics: Interview with Günther Grewendorf. Protosociology 6: 293-303.

.1995a. The Minimalist Program. Cambridge/Mass: MIT Press.

.1995b. Bare Phrase Structure. In: Gert Webelhuth (Org.) Government and Binding Theory and the Minimalist Program. Cambridge: Blackwell. .1998. Minimalist inquiries: the framework. MIT Occasional Papers in Linguistics 15.

.1999. Derivation by phase. Ms. MIT.

. 2000a. Linguistics and brain science. In: Alec Marantz, Yasushi Miyashita \& Wayne O’Neil (Eds.) Image, Language, Brain. Cambridge/ MA: MIT Press. 
. 2000b. The Architecture of Language. New Delhi: Oxford University Press.

. 2001. Beyond Explanatory Adequacy. MIT Occasional Papers in Linguistic 20.

2005. On phases. Mass: MIT Press.

. 2007. Of minds and language. Biolinguistics 1/1: 9-27.

Christianson, Kiel \& Fernanda Ferreira. 2005. Conceptual accessibility and sentence production in a free word order language (Odawa). Cognition 98: 105-125.

Christophe, Anne, Maria Teresa Guasti, Marina Nespor \& Brit Van Ooyen. 2003. Prosodic structure and syntactic acquisition: the case of the head-complement parameter. Developmental Science 6: 213-222.

CORRÊA, Letícia Maria Sicuro. 1995. The Relative Difficulty of Children's Comprehension of Relative Clauses: A Procedural Account. In: Keith Nelson \& Zita Règer (Eds.) Children's Language. v. 8. Hillsdale/N.Jersey: Lawrence Erlbaum Assoc.

. 2005a. Uma hipótese para a relação entre processador lingüístico e gramática numa perspectiva minimalista. Anais do IV Congresso Internacional da ABRALIN, 353-364 http://www.abralin.org/ publicacao/abralin2005.pdf.

. 2005b. Possíveis diálogos entre Teoria Lingüística e Psicolingüística: questões de processamento, aquisição e do Déficit Específico da Linguagem. In: Neusa Salim Miranda \& Maria Cristina Lobo Name (Orgs.) Lingüística e Cognição, Juiz de Fora: Editora da UFJF.

. 2006a. Conciliando processamento lingüístico e teoria de língua no estudo da Aquisição da Linguagem. In: Letícia Maria Sicuro Corrêa (Org.). Aquisição da Linguagem e Problemas do Desenvolvimento Lingüústico. Rio de Janeiro: Editora da PUC-RIO/ Edições Loyola.

. 2006b. Língua e Cognição: Antes e depois da revolução cognitiva In: Claudia Castellanos Pfeifer \& Jairo Nunes (Orgs.). Introdução às ciências da linguagem: linguagem, história e conhecimento. Campinas: Editora Pontes.

. 2007. O que, afinal, a criança adquire ao adquirir uma língua? A tarefa da aquisição da linguagem em três fases e o processamento de informação de interface pela criança. Letras de Hoje 42/1: 7-34.

.2008. Bootstrapping language acquisition from a minimalist standpoint: On the identification of phi-features in Brazilian Portuguese. In: Acrisio Pires \& Jason Rothman (eds.) Minimalist inquiries into child 
and adult language acquisition: Case studies across Portuguese. Studies on Language Acquisition. Berlin: Mouton de Gruyter. (em prep.)

. 2000. MABILIN - Módulos de Avaliação de Habilidades Lingüísticas (Projeto FAPERJ em andamento).

. \& Marina Rosa Ana Augusto. 2006. Computação lingüística no processamento on-line: em que medida uma derivação minimalista pode ser incorporada em modelos de processamento?? Texto para discussão, sessão Inter-GTs (Psicolingüística e Teoria da Gramática). XXI Encontro Nacional da ANPOLL, São Paulo, 19-21 de julho de 2006.

. \& Marina Rosa Ana Augusto. 2007. Computação lingüística no processamento on-line: soluções formais para a incorporação de uma derivação minimalista em modelos de processamento. Cadernos de Estudos Lingüísticos. 49 (2), 167-183.

. \& Marina Rosa Ana Augusto. 2007. Possible loci of SLI from a both linguistic and psycholinguistic perspective (trabalho originalmente apresentado no IX EUCLDIS (European Child Language Disorders Group. Royaumont, 2005). (submetido).

.\& Erica dos Santos Rodrigues. 2005. Erros de Atração no Processamento da Concordância sujeito-Verbo e a Questão da Autonomia do Formulador Sintático. In: Marcus Maia \& Ingrid Finger (Orgs.). Processamento da Linguagem. Pelotas: Editora da EDUCAT.

DeLL, Gary S. 1986. A Spreading activation theory of retrieval in sentence production. Psychological Review 93: 283-321.

EImAs, Peter D. 1974. Auditory and linguistic processing cues for place of articulation by infants. Perception and Psychopbysics 18: 341-347.

. 1996. The perception and representation of speech by infants. In: Morgan, James L. \& Katherine Demuth (Orgs.). Bootstrapping from Speech to Grammar in Early Acquisition. Mahwah/N.J.: Lawrence Erlbaum Associates.

Ferreira, Fernanda. 2000. Syntax in language production: An approach using tree-adjoining grammars. In: Linda Wheeldon (Ed.). Aspects of Language Production. Cambridge/MA: MIT Press.

Fodor, Janet Dean. 1998. Learning to parse? Journal of Psycholinguistic Research 27/2: 285-319.

. 2005. A Psicolingüística não pode escapar da prosódia. In: Marcus Maia \& Ingrid Finger (Orgs.) Processamento da Linguagem. Pelotas: Editora da EDUCAT. 
Fodor, Jerry Alan, Thomas Bever \& Merrill Garrett. 1974. The psychology of language: An introduction to psycholinguistics and generative grammar. New York: McGraw-Hill.

Fong, Sandiway. 2005. Computation with Probes and Goals: A Parsing Perspective. In Ana Maria Di Sciullo \& Rodolfo Delmonte (Orgs.). $U G$ and External Systems. Amsterdam: John Benjamins.

FrazIER, Lyn. 1979. On comprehending sentences: Syntactic parsing strategies. Tese de Doutorado. University of Connecticut: Indiana University Linguistics Club.

. 1987. Theories of sentence processing. In: Jay L. Garfield (Org.). Modularity in knowledge representation and natural language understanding. Cambridge/Mass: MIT Press. . \& Clifton. 1996. Construal. Cambridge/Mass: MIT Press.

FriedMANN, Na'ama. 2000. Moving verbs in agrammatic production. In: Roelien Bastiaanse \& Yosef Grodzinsky (Orgs.). Grammatical disorders in aphasia: A neurolinguistic perspective. London: Whurr.

. \& Rama Novogrodsky. 2004. The acquisition of Relative clause comprehension in Hebrew: A study of SLI and normal development. Journal of Child Language 31: 661-681.

. \& Rama Novogrodsky. (in press) Is the movement deficit in syntactic SLI related to traces or to thematic role transfer? Brain E Language. GarRetT, Merrill. 1975. The analysis of sentence production. In: Gordon Bower (Ed.). Psychology of learning and motivation 9. New York: Academic Press.

. 1980. Levels of processing in sentence production. In: Brian Butterworth (Ed.). Language Production I. London: Academic Press, $170-220$

.2000. Remarks on the architecture of language processing systems.

In: Yosef Grodzinsky, Lewis P. Shapiro \& David Swinney. Language and the Brain. Representation and Processing. San Diego: Academic Press. Gibson, Edward \& James Thomas. 1999. Memory Limits and Structural Forgetting: The perception of complex ungrammatical sentences as grammatical. Language and Cognitive Processes 14: 225-248.

Gordon, Peter, Randall Hendrick \& Marcus Jonhson. 2001. Memory interference during language processing. Journal of Experimental Psychology: Learning, Memory and Cognition 27: 1411-1423.

Gorell, Paul. 1995. Syntax and parsing. New York: Cambridge University Press. 
Gould, Stephen Jay. 1991. Exaptation: A crucial tool for evolutionary psychology. Journal of Social Issues 47: 43-65.

Gout, Ariel \& Anne Christophe. 2006. O papel do bootstrapping prosódico na aquisição da sintaxe e do léxico. In: Letícia Maria Sicuro Corrêa (Org.). Aquisição da Linguagem e Problemas do Desenvolvimento Lingüístico. Rio de Janeiro: Editora da PUC-Rio/ Edições Loyola.

HaKuTA, Kenji. 1981. Grammatical description versus configurational arrangement in language acquisition: The case of relative clauses in Japanese. Cognition 9: 197-236.

Hauser, Marc D, Noam Chomsky \& W. Tecumseh Fitch. 2002. The Faculty of language: what is it, who has it, and how did it evolve? Science 298: 1569-1579.

Hirsh-Pasek, Kathy, Roberta M. Golinkoff, Elizabeth A. Hennon, Mandy J. Maguire \& Jennifer Sootsman. 2006. O modelo emergentista de coalizão da aprendizagem de palavras: uma nova maneira de se pensar na psicologia do desenvolvimento. In: Letícia Maria Sicuro Corrêa (Org.). Aquisição da Linguagem e Problemas do Desenvolvimento Lingüístico. Rio de Janeiro: Editora da PUC-RIO/Edições Loyola.

Holmes, Virginia M., \& John Kevin O'REgan. 1981. Eye fixation patterns during the reading of relative clause sentences. Journal of Verbal Learning and Verbal Behavior 20: 417-430.

Hornstein, Norbert. 2001. Move! A Minimalist Theory of Construal. Oxford/ New York: Blackwell.

. Jairo Nunes \& Kleanthes K. Grohmann. 2005. Understanding Minimalism. Cambridge: Cambridge University Press.

JАСОВ, Pierre. 2003. Intentionality. Stanford Encyclopedia of Philosophy. http:/ /plato.stanford.edu/entries/intentionality/

Jakubowicz, Celia. 2003. Computational complexity and the acquisition of funcional categories by French-speaking children with SLI. Linguistics 41: 175-211.

. 2006. Hipóteses psicolingüísticas sobre a natureza do déficit especificamente lingüístico (DEL). In: Letícia Maria Sicuro Corrêa (Ed.). Aquisição da Linguagem e Desvios no Desenvolvimento Lingüístico. Editora da PUC-RIO/Edições Loyola.

Jenkins, Lyle. 2000. Biolinguistics. Cambridge: Cambridge University Press. JusczyK, Peter W. 1997. The Discovery of Spoken Language. Cambridge/Mass: MIT Press. 
Kayne, Richard S. 1994. The Antisymmetry of Syntax. Cambridge, Mass: MIT Press.

Kempen, Gerard \& Edward Hoencamp. 1982. Incremental Sentence Generation: Implications for the Structure of a Syntactic Processor. In: Jan Horecky (Ed.). Proceedings of the Ninth International Conference on Computational Linguistics. Amsterdam: North-Holland.

. 1987. An incremental procedural grammar for sentence formulation. Cognitive Science 11: 201-258.

Kimball, John. 1973. Seven Principles of Surface Structure Parsing in natural language. Cognition 2: 15-47.

KING, Jonathan \& Marcel JusT. 1991. Individual differences in syntactic processing: The role of working memory. Journal of Memory and Language 30: 580-602.

Kluender, Robert \& Marta KutAs. 1993. Bridging the gap: Evidence from ERPs on the processing of unbounded dependencies. Journal of Cognitive Neuroscience 5/2: 196-214.

KnIGHT, Kevin. 1989. Unification: A Multidisciplinary Survey. ACM Computing Surveys 21/1: 93-124.

KonieCZny, Lars. 2000. Locality and parsing complexity. Journal of Psycholinguistic Research, 29: 627-645.

LaUrence, Stephen \& Eric Margolis. 1999. Concepts and cognitive science. In: Eric Margolis \& Stephen Laurence (Eds.). Concepts: Core readings Cambridge/Mass: MIT Press.

LeONARD, Laurence. 1998. Children with Specific Language Impairment. Cambridge/ Massachusetts: MIT Press.

LEVELT, Willem J.M. 1989. Speaking: From Intention to Articulation. Cambridge/Mass: MIT Press.

. 1995. The ability to speak: From intentions to spoken words. European

Review. Interdisciplinary Journal of the Academia Europea 3:13-23. ., Ardie Roelofs \& Antje Meyer. 2001. A theory of lexical access in speech production. Behavioral and Brain Sciences

http://www.bbsonline.org/documents/a/00/00/05/26/

Lima, Ricardo J., Letícia Maria Sicuro CorrêA \& Marina Rosa Ana Augusto. 2007. Padrões de seletividade na produção agramática e distinção entre movimentos sintáticos na computação on-line. (submetido)

Lourenço-Gomes, Maria do Carmo, Marcus Maia E João Moraes. 2005. Prosódia Implícita na Leitura Silenciosa: Um Estudo com Orações Relativas Estruturalmente Ambíguas. In: Marcus Maia E Ingrid Finger (Orgs.). Processamento da Linguagem. Pelotas: Editora da EDUCAT. 
LyCan, William G. 2003. Chomsky on the Mind-Body Problem. In: Louise Antony \& Norbert Hornstein (Orgs.) Chomsky and his Critics. Oxford/ New York: Blackwell Publishing.

MACNAMARA, John. 1977. On the relationship between language learning and thought. In: John Macnamara (Org.). Language Learning and Thought. NewYork: Academic Press.

MAK, Willem M., Wietske VONK E Herbert SCHRIEFERS. 2002. The influence of animacy on relative clause processing. Journal of Memory and Language 47: 50-68.

MARr, David. 1982. Vision: A computational investigation into the human representation and processing of visual information. New York: W. H. Freeman.

MCDonaLD, Janet L., Kathryn BocK \& Michael KeLLY. 1993. Word and World order: semantic, phonological and metrical determinants of serial position. Cognitive Psychology 23: 188-230.

McMAHON, Lee Edward. 1963. Grammatical analysis as part of understanding a sentence. $\mathrm{PhD}$ Thesis, Harvard University.

MeHLER, Jacques. 1981. The role of syllables in speech processing: Infant and adult data. Philosophical Transactions of the Royal Society. London.

, Peter Jusczyk, Ghislaine Lambertz, Nilofar Halsted, Jociane Bertoncini \& Claudine Amiel-Tison, C. 1988. A Precursor of Language Acquisition in Young Infants. Cognition 29: 143-178.

Miller, George A. \& Noam Chomsky. 1963. Finitary models of language users. In: Duncan Luce, Robert Bush \& Eugene Galanter. (Orgs). Handbook of Mathematical Psychology 2. New York: J. Wiley.

. \& Kathryn O. Mckean. 1964. A chronometric study of some relations between sentences. Quartely Journal of Experimental Psychology 16: 297-308.

Morgan, James L. \& Katherine Demuth. 1996. Signal to Syntax: an overview. In: James L. Morgan \& Katherine Demuth (Orgs.). Signal to Syntax: Bootstrapping from speech to grammar in early acquisition. Mahwah/ New Jersey: Lawrence Erlbaum Associates.

Müller, Horst M., Jonathan W. KING \& Marta Kutas. 1997. Event-related potentials elicited by spoken relative clauses. Cognitive Brain Research 5: 193-203.

Nicol, Janet. \& David SwINNEY. 1989. The role of structure in coreference assignment during sentence comprehension. Journal of Psycholinguistic Research: Special Issue on Sentence Processing 18/1: 5-24. 
PhiluIPS, Colin. 1996. Order and Structures. PhD Thesis, MIT.

. 2003a. Linguistics and linking problems. In: Mabel Rice \& Steven

F. Warren. (Eds.). Developmental Language Disorders: From Phenotypes to Etiologies. Mahwah/ N.J.: Lawrence Erlbaum.

. 2003b. Linear order and constituency. Linguistic Inquiry 34: 37-90.

Place, Ullin T. 1960. Materialism as a scientific hypothesis. Philosophical Review 69: 101-104.

Platzack, Christer. 1998. The initial hypothesis of syntax: a minimalist perspective on language acquistion and attrition In: Harald Clahsen (Ed.). Generative perspectives on language acquisition. Amsterdam: Jonh Benjamin.

Polikarov, Azarya. 1995. Concerning the integration of sciences: Kinds and stages. Journal for General Philosophy of Science 26/2: 297-312.

Pollard, Carl \& Ivan A. SAG. 1987. Information-based syntax and semantics.

Stanford, CA: Center for the Study of Language and Information, CLSI Lecture Notes 13, 1. Fundamentals.

. 1994. Head-Driven Phrase Structure Grammar. Chicago: University Chicago Press.

Pylyshyn, Zenon. 1984. Computation and Cognition. Cambridge/MA: Bradford/MIT.

Rodrigues, Erica dos Santos. 2006. Processamento da concordância de número entre sujeito e verbo na produção de sentenças. Tese de Doutorado, PUCRio.

SilveIra, Marisa S. 2002. O Déficit Especificamente Lingüístico (DEL) e uma avaliação preliminar de sua manifestação em crianças falantes de português. Dissertação de Mestrado, PUC-Rio.

SCHLESINGER, Ischak M. 1975. Why a sentence in which a sentence in which a sentence is embedded is embedded is difficult. International Journal of Psycholinguistics 4: 53-66.

Stobin, Dan. I1966. The acquisition of Russian as a native language. In: F. Smith \& G. A. Miller (Eds.). The genesis of language: A psycholinguistic approach. Cambridge/ MA: MIT Press.

SMART, Jack J. C. 1981. Physicalism and Emergence. Neuroscience 6:109-113. Traxler, Matthew. J., Robin K. Morris \& Rachel E. Seely. 2002. Processing subject and object relative clauses: evidence from eye movements. Journal of Memory and Language 47: 69-90.

Townsend, David. J. \& Thomas G. Bever. 2001. Sentence Comprehension: The Integration of Habits and Rules. Cambridge, Mass: MIT Press. 
UriagereKa, Juan. 1999. Multiple spell-out. In: Samuel David Epstein \& Norbert Hornstein (Eds.) Working minimalism. Cambridge/Mass: MIT Press.

Vigliocco, Gabriela \& Janet Nicol. 1998. Separating hierarchical relations and word order in language production: Is proximity concord syntactic or linear? Cognition 68: B13-B29.

Vijay K. SHANKer \& Aravind K. Joshi. 1985. Some computational properties of Tree Adjoining Grammars. Trabalho apresentado em The 23rd ACL Annual Meeting: 82-93.

Wanner, Eric \& Michael Maratsos. 1978. An ATN approach to comprehension. In: Morris Halle, Joan Bresnan \& George A. Miller (Orgs.). Linguistic Theory and Psychological Reality. Cambridge: MIT Press.

Warren, Tessa \& Gibson, Edward. 2002. The influence of referential processing on sentence complexity. Cognition 85: 79-112.

Weinberg, Amy \& Berwick, R. 1984. The Grammatical Basis of Linguistic Performance. MIT Press. 